\title{
From Material Level to Structural Use of Mineral-Based Composites-An Overview
}

\author{
Katalin Orosz, ${ }^{1,2}$ Thomas Blanksvärd, ${ }^{3}$ Björn Täljsten,, ${ }^{1,3}$ and Gregor Fischer ${ }^{1}$ \\ ${ }^{1}$ Department of Civil Engineering, Technical University of Denmark, Brovej, Building 18, 2800 Kgs. Lyngby, Denmark \\ ${ }^{2}$ Group Material Technology, Norut Narvik Ltd, P.O. Box 250, 8504 Narvik, Norway \\ ${ }^{3}$ Division of Structural Engineering, Luleå University of Technology, 97187 Luleå, Sweden
}

Correspondence should be addressed to Katalin Orosz, katalinorosz01@gmail.com

Received 22 April 2009; Revised 17 January 2010; Accepted 4 March 2010

Academic Editor: Tarun Kant

Copyright (c) 2010 Katalin Orosz et al. This is an open access article distributed under the Creative Commons Attribution License, which permits unrestricted use, distribution, and reproduction in any medium, provided the original work is properly cited.

\begin{abstract}
This paper surveys different material combinations and applications in the field of mineral-based strengthening of concrete structures. Focus is placed on mechanical behaviour on material and component levels in different cementitious composites; with the intention of systematically maping the applicable materials and material combinations for mineral-based strengthening. A comprehensive description of a particular strengthening system developed in Sweden and Denmark, denominated as Mineralbased Composites (MBCs), together with tests from composite material properties to structural elements is given. From tests and survey it can be concluded that the use of mineral-based strengthening system can be effectively used to increase the load bearing capacity of the strengthened structure. The paper concludes with suggestions on further development in the field of mineral-based strengthening.
\end{abstract}

\section{Introduction}

The existing civil engineering infrastructure is a very important element of the economical potential of a majority of the countries worldwide. A large number of today's buildings, transportation systems, and utility facilities are built with reinforced concrete and many of these systems are currently reaching the end of their expected service life. Additionally, increased loads and traffic flows, reuse, and ongoing deterioration even affect the durability of structures that are less than 20 years old.

There exist several repair and strengthening methods that can be applied to existing concrete structures for this purpose, such as cross section enlargement of critical elements, span shortening with additional supports, external/internal post tensioning, and steel plate bonding or strengthening with fibre-reinforced polymer (FRP) composites. Since the end of the 1980s, the use of FRP has been researched and applied increasingly for the rehabilitation of existing concrete structures. Externally epoxy-bonded FRP systems have been proven to be an effective strengthening method in repairing or strengthening structures and a large amount of literature is published on this topic; see, for example, [1-7]. FRP reinforcements can be used in numerous ways to strengthen a structure, For example, by bonding plates or sheets with a high-quality epoxy to the surface of concrete, timber, or even steel structures. There are also methods to wrap columns for enhanced ductility and strengthening systems where FRP rods are embedded in the concrete surface. Systems replacing the epoxy with polymer-modified mortars have been recently developed. For example, continuous fibre sheets can be embedded in a layer of mortar to provide, for example, confinement to a column; however, lately these sheets have been replaced by textiles due to bond issues related to difficulties with penetration as described in [8]. Biaxial or multidimensional FRP textiles are used in Textile-Reinforced concrete (TRC) $[9,10]$ systems or Textile-Reinforced mortar (TRM) jacketing, see; for example, [11].

In this paper a state-of-the-art report using mineralbased FRP strengthening systems is presented together with information about recent research at Luleå University of Technology (LTU), Sweden, and Technical University of Denmark (DTU). The literature survey is selective to published applications in which a fibre component has been 


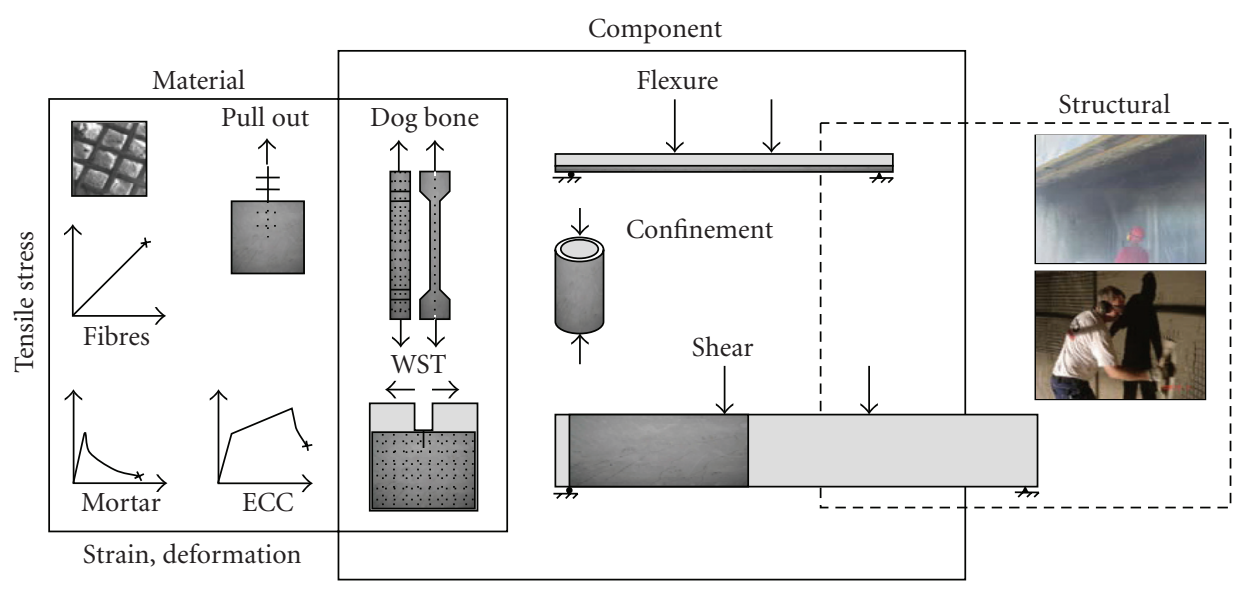

FIGURE 1: From material to structural level.

used together with a cementitious bonding agent, referred to as "mineral-based strengthening" in general. The authors also involved research and results from the field of ductile cementitious mortars which could be used together with an FRP component resulting in a high-performance strengthening material. The research significance within this paper is the mapping of possible design of different mineral-based strengthening systems. In addition, a systematic mapping of the novel strengthening system named mineral-based composites (MBCs), developed at LTU and DTU, going from material science to composite behaviour and some outlines for applications to existing structures are presented.

\section{Definition and Development of Mineral-Based Strengthening Systems}

"Mineral-based strengthening" in a broader perspective may be referred to any kind of a strengthening system in which a fibre component is embedded into a mineral-based binder to repair or strengthen existing concrete structures. Mineral-based strengthening in this context would include applications as surveyed in Section 3 from textile-reinforced mortar/concrete through fibre-reinforced cement to FRP grid applications.

Mineral-based strengthening systems are originally derived from other externally bonded FRP systems. The most commonly used adhesive to bond the FRP element to the surface of the structure (mainly concrete) is the epoxy adhesive. The use of epoxy has proven to give excellent force transfer. It bonds to the majority of surfaces (concrete, steel, timber, etc.) and shows to be durable and resistant to many different environments. However, some drawbacks can be identified. Firstly, epoxy as a bonding agent may create problem in the working environment, secondly, epoxy is recommended to have a minimum application temperature, often above $10^{\circ} \mathrm{C}$, and thirdly, epoxy creates diffusion-closed (sealed) surfaces which may imply moisture and freeze/thaw problems for concrete structures. There might also be bond problems applying epoxy to wet or humid surfaces. To avoid some of these problems alternative strengthening systems have been researched and are currently being developed.
In mineral-based strengthening systems, the traditional epoxy bonding agent to adhere the FRP to the concrete surface is being replaced by cementitious matrices to bond the fibre material to the concrete surface. Mineral-based strengthening systems are made by replacing part of the cement hydrate binder of conventional mortar with polymers which, with the addition of fibre composites, become a high-performance external strengthening system for existing concrete structures.

\section{Concept of Mineral-Based Strengthening}

Mineral-based strengthening systems are dealt within three different levels. At the material level, the raw materials used in a mineral-based composite system such as binders (different quasibrittle or strain hardening mortars), FRP reinforcement (dry fibres, textiles, grids) and the most important properties of those are defined (Figure 1). At the component level, larger strengthened elements are discussed, for example, beams strengthened in flexure and shear. At the level of structural behaviour, field applications can be mentioned.

The intersection between material and component level would contain the different interactions between constituents and the effects of those on the structural behaviour (bond transfer mechanisms, fibre bridging and strain hardening).

3.1. Materials for Mineral-Based Strengthening. A list of requirements is proposed in [11] which should be met for a successful and efficient mineral-based strengthening. The mortar phase should have very low shrinkage deformations, high workability (application should be possible using a trowel, or shotcreted), high viscosity (application should not be problematic on vertical or overhead surfaces), low rate of workability loss (application of each mortar layer should be possible while the previous one is still in a fresh state), and sufficient shear (hence tensile) strength, in order to avoid premature debonding. In case E-glass fibre textiles are used, the mortar-based matrix should be of low alkalinity. $\mathrm{Li}$ [12], also adds a few requirements on 


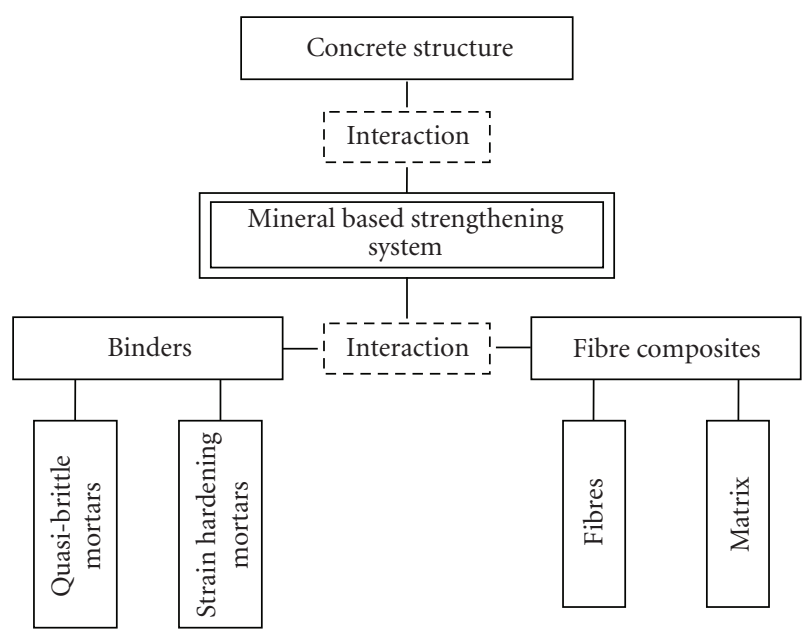

FIgURE 2: Overview of the constituents and possible interaction in mineral-based strengthening systems.

the "future concrete" which the authors feel relevant for a concrete-like repair and strengthening material as well: the "concrete" should be highly ductile with the ability of "yield" like a metal when overloaded to prevent unpredictable and sudden failure, highly durable and sustainable. These justify involving ductile mortars into the MBC system.

Mapping of the materials that have been or are promising to be used in mineral-based strengthening systems is shown in Figure 2. The integrated materials in the mineral-based strengthening systems can be divided in two main groups, binders and fibre composites. The components used in practical applications are detailed in the following.

3.1.1. Binders. Binders in practical applications are either quasibrittle, conventional polymer-modified or more ductile, strain hardening mortars.

Quasibrittle Mortars. Polymer-modified mortar (PMM) is the most widely used [13], suitable mortar in a mineralbased strengthening system. Polymeric admixture, or cement modifier, is defined as an admixture which consists of a polymeric compound that acts as a main ingredient when modifying or improving the properties such as strength, deformation, bond strength, or durability of mortars and concretes. The polymer-modified mortars or concretes therefore contain two types of binder, the hydraulic cement and the polymeric admixture. Polymeric admixtures can be latexes, powdered emulsions, water soluble polymers and liquid resins. Adding polymeric compounds to the finegrained mortar phase is also common to enhance mechanical properties of Textile-Reinforced concrete (TRC) or mortar. In [14], improved interfacial bond is achieved by a secondary polymeric cohesive matrix within the mortar phase. In general, the properties of a polymer-modified mortar (or concrete) depend significantly on the polymer content or polymer-cement $(\mathrm{P} / \mathrm{C})$ ratio rather than the water-cement ratio compared with ordinary cement mortar [15].

Increasing the $\mathrm{P} / \mathrm{C}$ ratio to about $10 \%-15 \%$ by weight has shown to increase the flexural strength. A P/C ratio higher than $15 \%$ by weight decreases the mechanical strength $[15,16]$. Another source, [17] states that an addition of polymeric dispersion up to even $20 \%$ by weight results in a higher tensile strength of the (Textile-Reinforced) concrete.

To further enhance the properties of a PMM, for example, workability, flowability, mechanical properties, and so forth, of the mortars, superplasticizers, silica fume, fly ash and reinforcing fibres can be used.

Fibres in the matrix can be chopped or milled fibres. The fibres must be easily dispersed in the mixture, must have suitable mechanical properties, and must be durable in the highly alkaline cement matrix. They are randomly (in a good mix, uniformly) distributed throughout the mortar/concrete. Continuous fibres are more effective in increasing strength in a certain direction compared to randomly distributed short fibres, but they are not easily mixed into the cement matrix and their high cost does not allow them to be widely used. Different types of fibres are currently used such as steel, glass, carbon, polyvinyl-alcohol (PVA), polypropylene, nylon and natural fibres depending on the structural needs. Using a small percentage of carbon fibre addition $(\sim 0.5 \%)$, a considerable increase in flexural strength is achieved relative to unreinforced mortar [18]. Other researchers have investigated new type of fibres, such as ceramic fibres [19]. The results show that the flexural strength of mortar can be increased and also the durability of this ceramic fibre-reinforced mortar is much better than that of alkali-resistant (AR) glass fibre. The use of steel fibres is the most common solution to enhance toughness of a steel fibre-reinforced concrete (conventional FRC). For enhanced ductility, first cracking strength or ultimate tensile strength, other types of fibres may be more suitable. The addition of small volume fractions of synthetic fibres (up to $2 \%$ ) to the mortar can improve the toughness of the mortar [20]. Among these fibres, the polypropylene fibres are very popular in concrete and the nylon fibres are recently becoming more widely used [21]. The propylene fibres reinforce the concrete performance under flexure, tension, impact blows and plastic shrinkage cracking. On the other hand, the nylon fibres improve the performance after the presence of cracks and sustained high stresses. In [22], both types of fibres were compared and the results showed a better improvement of the properties when using the nylon fibres than the polypropylene fibres. Other researches $[23,24]$ are focusing on the use of recycled PET (polyethylene terephthalate). PET fibres made from beverage bottles were used successfully up to $3 \%$ in (normal) concrete [23]. Another study on the durability in aggressive environments of a PETreinforced concrete [24] emphasizes the sustainability and environmentally friendliness of such concretes since the PET fibre has a long decomposition time (over 100 years to completely degrade).

Some supplementary materials should be used for counteracting the insufficiencies brought about by the addition of fibres, such as increase in porosity or decrease in compressive strength. For example, substituting a part of the cement $(20 \%)$ by silica fume increases the compressive strength of the resulting mortar and provides a reduction of porosity, which leads to an increase of the flexural strength. Adding 
silica fume in concretes also increase the interfacial bond strength and interfacial fracture energy by about 100\% due to its smaller particle size and thereby the ability to increase the density of the microstructure of a mix $[25,26]$.

In concrete prepared with ordinary Portland cement, the interfaces between the hydrated cement matrix and the aggregates are the weakest link [27]. The incorporation of industrial by-products such as fly ash in concretes can significantly enhance basic properties in both the fresh and hardened states $[28,29]$. It is well known that blending cement with fly ash or other supplementary cementing materials improves the rheological properties of the fresh concrete and the engineering properties of hardened concrete [3032]. Fly ash in Textile-Reinforced concrete is widely used to densify the grain structure [33] resulting in an improved bond between textile and concrete. Superplasticizers can also be used to improve consistency and workability.

Strain Hardening Mortars. Engineered Cementitious Composites (ECCs) are another type of binder which can be used together with an FRP component [34]. Both in the case of repair and strengthening, the failure mechanisms that lead to the need for repair/retrofit of a structure often involve fracture. This can be overcome by materials with improved toughness, ultimate tensile strength and ductility, which justifies involving ECC into the FRP strengthening. This micromechanically designed material invented in the early 1990s represents a particular class of HPFRCC (HighPerformance Fibre-reinforced Cementitious Composites), exhibiting strain hardening behaviour and multiple cracking during the inelastic deformation process [35]. Since its introduction, ECC has undergone major evolution in both material development and the range of applications. Recently, it is often referred to as SHCC (strain hardening cementitious composites) due to its tensile (pseudo) strain hardening effect of (steel reinforced) ECC, see more in detail later, which has been previously documented by Fischer and Li [36].

Besides common ingredients of cementitious composites such as cement, sand, fly ash, water and additives, ECC utilizes short, randomly oriented polymeric fibres (e.g., polyethylene, polyvinyl alcohol) at moderate volume fractions $(1.5 \%-2 \%)$. In contrast to some other types of fibres, there is a strong chemical bond between PVA and mortar which needs to be reduced [37]. This is done by a chemical coating applied on the fibre surface and additional fly ash in the mix in order to prevent premature PVA fibre rupture and thus achieve a more ductile failure mode, characterized by pull-out from the cement matrix.

The tensile strain capacity of ECC is several hundred times that of normal concrete [12] and the fracture toughness of ECC is similar to that of aluminium alloys [38]. Furthermore, the material remains ductile even when subject to high shear stresses [39]. The compressive strength of ECC ranges from 40 to $80 \mathrm{MPa}$ depending on mix composition, the high end similar to that of high strength concrete. ECC has typically an ultimate tensile strength of 5-8 MPa and a strain capacity ranging from $3 \%$ to $5 \%$.
There are a number of characteristics of ECC that make it attractive as a repair material. According to $\mathrm{Li}$ [40], the unique feature of ECC is its ultra high ductility. This implies that structural failure by fracture is less likely in comparison to normal concrete or steel fibre-reinforced concrete (FRCs). As a consequence, ECC has been used in a wide range of applications where ductility and/or energy absorption performance or damage tolerance of the material is an important criterion (seismic and nonseismic structural applications, see, e.g., [41-45]. In contrast to quasibrittle repair materials, ECC can eliminate premature delamination of the strengthening layer or surface spalling in an ECC/concrete repaired system [46]. Spall resistance of ECC in the surroundings of a corroded rebar in slabs has been investigated by Kanda et al. [47], where ECC accommodated the expansion by a "plastic yielding" process through radial microcracking [12]. Interface defects can be absorbed into the ECC layer and arrested without forming spalls, thus extending the service life [38]. Suthiwarapirak et al. [48] showed that ECC has significantly higher fatigue resistance than that of commonly used repair materials such as polymer mortars. It also has a good freeze-thaw resistance and restrained shrinkage crack control [41]. ECC-reinforced shear beams behaved in a ductile manner even without additional (steel) shear reinforcement and remained ductile even for short span shear elements which typically fail in a brittle manner with normal concrete [49]. Under shear, ECC develops multiple cracking with cracks aligned normal to the principal tensile direction. Because the tensile behaviour of ECC is ductile, the shear response is correspondingly ductile. ECC as a strengthening material also offers excellent crack control. When an ECC structural element is loaded in flexure or shear beyond the elastic range, the inelastic deformation is associated with microcracking with continued load carrying capacity across these cracks [40]. The microcrack width is dependent on the type of fibre and interface properties (generally less than 100 micron when PVA fibre is used). The tight crack width in ECC has advantageous implications on structural durability [12]. When used as strengthening or repair material, fine cracks also prevent penetration of substances [50]. The spacing between multiple cracks in a typical ECC is on the order of several $\mathrm{mm}$, while the crack widths are limited to the order of $200 \mu \mathrm{m}$. In standalone applications, maximum crack width in ECC is a material property independent of the embedded reinforcement, unlike in RC or conventional FRC in which cracks widths are influenced by the steel reinforcement [12]. However, crack distribution of ECC as repair material is more concentrated adjacent to an existing crack in the base substrate [12].

"Flowability" or "self-compactability" of ECC refers to the ability of the material that it can flow under its own weight and fill the formwork properly. Despite the presence of (short, chopped, randomly oriented, typically PVA or PE) fibres, a self-compacting ECC is able to fill in each corner of the formwork without external vibration required [51]. This would also ensure a good bond to the embedded reinforcement (such as steel or FRP). 


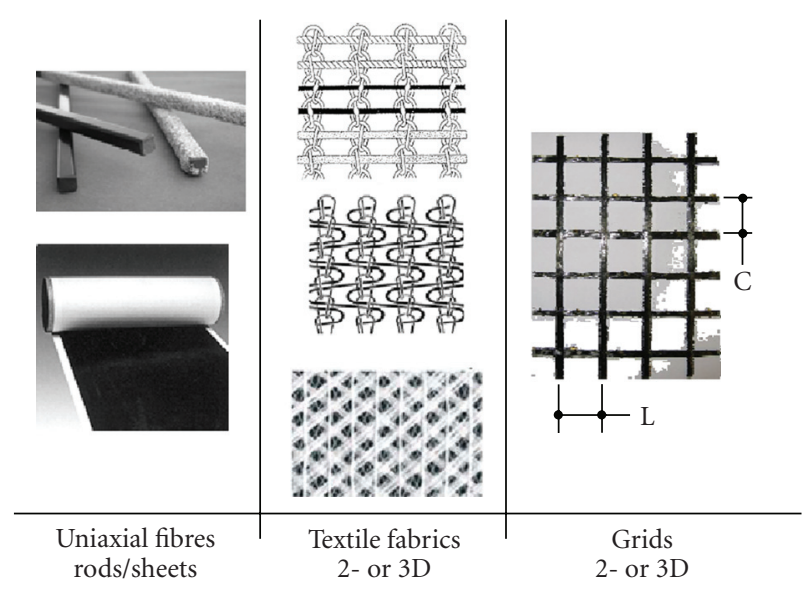

Figure 3: Different types of fibre composites.

3.1.2. Fibre Composites. Commonly used FRP reinforcements are shown in Figure 3. FRP rods are typically used as internal reinforcement or for near-surface mounted reinforcement (NSMR). Other pultruded profiles used are thin composite plates with a typical cross section of $1.4 \times$ $80 \mathrm{~mm}$; however none of these systems will be detailed within this paper. Uniaxial fibres or fibre sheets, textiles and grids used together with mineral-based bonding agents are other types of FRP reinforcement systems, these systems are described more in detail below.

Fabrics and Textiles (Knitted, Woven, or Unwoven). Different kinds of fibres used as FRP reinforcement and their mechanical properties are detailed, for example, in $[52,53]$. There exist a few continuous long fibre applications, where nonimpregnated unidirectional fibres may be embedded in a mortar phase [21], but the impregnation of continuous fibre sheets with mortars is very difficult resulting in a poor bond between fibre and mortar [8]. Fibres used in most mineralbased strengthening systems usually come in the form of a textile or fabric (woven or knitted) or grid (with rigid joints), where the latter is impregnated and held together by an epoxy resin which also shapes the composite.

Fabrics are unidirectional or multidirectional FRP composites. They are widely used in Textile-Reinforced concrete systems. The most commonly used textiles are the bidirectional woven fabrics, in which the yarns are woven together crossing them orthogonally, having a width of $300-600 \mathrm{~mm}$, in large spools cut at the workplace. The density of the yarns directly affects the penetrability of the adhesive into the fabric, higher density leads to lower penetrability as the mechanical interlock acts through the fabric openings [11]. Woven fabrics are easy to adapt to any surface which makes them very suitable for wrapping (U-warp or full wrap) or confinement. The flexible shape also represents some disadvantages. The reinforcing efficiency is lower than that in straight yarns due to the crimped geometry of the woven fibres; however, this crimped geometry is advantageous in providing mechanical anchoring between the woven fabric and the cement matrix in a polymermodified mortar. Fabrics having relatively complicated yarn shapes may enhance the bonding and improve the composite performance [11]. However, very complex textile geometries may cause premature failure of some of the yarns resulting in lower strength than the nominal strength of the fibrous phase would be, as reported in [54].

Bi- and Triaxial Grids with Rigid Joints. An FRP grid is a multidirectional prefabricated composite. For externally bonded reinforcement, grids are made of continuous fibres alternating in two directions and impregnated with a resin to form a 2D-cross laminate grid structure with rigid joints. The resin is usually epoxy and its role is to hold the fibres together and shaping the composite. The fibre amount and grid spacing often vary in the two perpendicular directions. FRP grids are typically produced in large rolls and then cut into the required dimensions. Compared to woven fabrics, FRP grids have improved mechanical properties and in general, have more rigid connection points. The improved performance is due to the aligned fibres in a certain (predefined) direction and that there are no unpenetrated fibres or fibre bundles with would prematurely fail (further discussed in Section 4.2 under TRC). Thinner grids are flexible and can be adapted to curved surfaces.

\section{Existing Mineral-Based Strengthening Systems}

4.1. Continuous Dry Fibres. The use of continuous dry fibres is published in [55] where a pretreatment with silica fume and high amounts of polymers improved the bond between carbon fibres and cementitious matrices. It was found that a pretreatment with silica fume and relatively high amounts of polymers improved the bond behaviour of carbon fibre to the cement. Another report [56] has been published on large-scale tests of ordinary concrete beams strengthened with a cementitious fibre composite where the strengthening composite consisted of a unidirectional sheet of continuous dry carbon fibres and a polymer-modified mortar, applied by hand lay-up method. Both flexural and shear strengthening were investigated. From the tests it was concluded that the method works and that considerable strengthening effects can be achieved. However, in comparison with epoxybonded carbon fibre sheets using the same amount of carbon fibre, the strengthening effect for the mineral-based composite strengthening system was approximately half. The reason for this is most likely due to the reduced interfacial bond strength between the mortar and the carbon fibrereinforcement. This is also emphasized by [57], where it was found that the loading capacity of the cementitious carbon fibre composite is influenced by the amount of fibres in the tow. If the cementitious matrix penetrated into the interior of the carbon fibre tow, a higher number of filaments would be active during loading, leading to the increase in load carrying capacity.

Another way of using continuous dry fibres, usually in the form of sheets is the fibre-reinforced composites (FRCs) strengthening system (which may also use dry fabrics), as described by, for example, [58]. Depending on the geometry of the fibres and the strengthening purpose, the composite 
plates can be made as thin as $2 \mathrm{~mm}$. The sheet or fabric is cut into chosen dimensions and the fibre geometry is submerged into cement slurry (matrix) for a better penetration. The impregnated sheet or fabric is then removed from the slurry and immediately bonded to the concrete surface. An improved penetration of the matrix into the fibres can be achieved by using multiple layers of continuous carbon fibres where all single layers were impregnated in cementitious slurry before bonded to the concrete surface. This procedure was also suggested in [51]; however not executed.

\subsection{Textile-Reinforced Mortar (TRM) or Textile-Reinforced} Concrete (TRC). Textile-Reinforced Concrete (TRC) is made from a cementitious matrix and layers of oriented, continuous fibres (technical textiles) as for reinforcement. Here TRC is only discussed as a strengthening material and not as a material also suitable for stand-alone applications such as thin shells. The most commonly used bonding agent for applying the textile on the structure is the fine grained concrete or mineral-based mortar which has a grain size of less than $1 \mathrm{~mm}$ and provides high strength and flowable consistencies. Less than $2 \mathrm{~mm}$ of concrete or mortar thickness is needed between textile layers due to the small maximum aggregate size of the concrete mix [9]. Alkaliresistant glass (AR-glass) or carbon is used most often as the fibrous material. The fibres can be in the form of a woven textile or be unidirectional and held together by a yarn in the perpendicular direction in order to make the material easier to work with. The fabrics can be manufactured with a maximum number of four reinforcing directions depending on the load direction [9] and can therefore be tailored (the filaments are intentionally aligned in the direction of the tensile stresses leading to an increase in their effectiveness). There are several designs of textile fabrics depending on the load case and the positioning of the fabrics. Most fabrics are bi- or multiaxial warp knits and woven fabrics since they offer a great flexibility of properties and are suited for many cases.

In a TRC strengthening system, the transfer of the bond forces from one layer to another through the bonding joint must be guaranteed to ensure a full composite action. The bond behaviour of TRC is a complex property that depends on both the textile and the matrix. Due to the reinforcement geometry, only the outer filaments are directly in contact with the concrete, hence the load bearing capacity of a TRC depends mainly on the proportion of the outer to the inner filaments, and just a certain part of the tensile strength of the concrete can be activated due to the limited contact surface $[14,59]$. Significant improvement in load capacity can be achieved if the textile is previously penetrated with liquid polymers [17, 59] or epoxy- resins [17]. However, there is a risk that in an impregnated textile, a higher number of activated filaments would lead to abrupt failure of all filaments when the tensile strength of those is exceeded [17]. The same study also highlights that the tensile strength of a TRC (dogbone) specimen can be increased most effectively by both impregnating the textiles with polymers and adding polymer modifiers to the concrete.
TRC systems exhibiting mechanisms of distributed cracking and strain hardening behaviour (see Section 5) have been used for stand-alone structural applications such as extremely thin and slender structures [60], or for repair and strengthening of existing structural members $[9,10]$. Confinement strengthening of short columns both with epoxy and cement-based mortars has been investigated by [8]. Effectiveness of the TRM jacketing compared to the epoxy-impregnated counterparts resulted in a reduced effectiveness ( $80 \%$ for strength and $50 \%$ for ultimate strain). The strengthening effect increased with the number of confining layers and was highly dependent on the tensile strength of the applied cement mortar. Failure was more ductile in case of the TRM jacketing than in the epoxy-bonded jackets due to the slowly progressing fracture of individual fibre bundles. Shear strengthening of concrete beams has been examined in [61] on six identical RC beams with different bonding agents (epoxy and cement matrix), one or two layers of textile in different arrangements (conventional wrapping and spirally applied textiles). Two layers of mortar-impregnated Textile-Reinforcement in the form of either conventional jackets or spirally applied strips were sufficient to increase the shear capacity of the beams tested more than $100 \%$ over the unstrengthened beam, preventing sudden shear failures and allowing activation of flexural yielding (as was the case with the resin-based jacket). The TRM system; however, was found to be about 50\% less effective than the FRPstrengthened beam. Other experiments [9, 10, 62] have been carried out on T-beams which were designed with minimum shear reinforcement but a great amount of longitudinal flexural reinforcement in order to prevent flexural failure. The strengthening fabric was a multiaxial textile applied as a U-wrap in an angle of $45^{\circ}$ to the load direction, aligned with the principal stresses in the web of the T-beam to be strengthened. Varying parameters were the number of textile layers (2-6) placed with or without mechanical anchorage in the compression zone. The adhesive tensile load carrying capacity is crucial in the performance of the system - this determines how many layers can be anchored to the web without any additional mechanical anchorage. Tests revealed the importance of mechanically anchoring of the reinforcement. A load increase could be achieved with a few layers of textile even without anchorage to the compressive zone; however, when the adhesive tensile bond between the web and the reinforcement was exceeded, the TRC layers peeled away and therefore the reinforcement fails.

4.3. Mineral-Based Composites (MBCs). MBCs (mineralbased composites) are defined as a system in which a FRP grid is applied onto the surface of the structure to be strengthened with a cement-based mortar as bonding matrix. MBC "inherits" the properties and behaviour of its constituents, for example, brittleness or tension softening behaviour when the linear elastic fibre material is used together with quasibrittle cementitious binders. However, its behaviour can significantly be changed/altered and the material can be enforced to exhibit more ductility, multiple cracking or strain hardening in tension in a modified 
MBC where the mortar is a PVA-reinforced engineered cementitious composite (ECC) $[63,64]$. In the recent development of MBC, two strengthening approaches meet and result in a high-performance hybrid strengthening material. One is finding the most suitable combinations of a FRP reinforcement and an existing mortar (which, depending on the application may be ordinary or polymer-modified mortar), and the other one is to strengthen/develop the mortar itself with different short fibres (in practice, mostly PVA) or involve existing, ductile mortars in order to improve the interaction between grid and mortar, tensile properties of the composite, crack spacing and crack widths, ductility and also if possible, fracture energy.

The FRP in MBC applications is normally a twodimensional carbon fibre grid. As matrix, polymer-modified quasibrittle mortars (PMMs) are typically used. Between the two components little or no chemical bond exists. Therefore the bond strongly relies on mechanical bond, contrary to epoxy-based FRP systems. The precut CFRP grid with varying grid spacing and thickness is embedded between two relatively thin layers of mortar.

To achieve a good bond between the base concrete and the mortar, the surface of the base concrete needs to be roughened, for example, by sandblasting or water jetting, in order to remove the cement laitance. The surface preparation method normally is sandblasting. The strengthening layers can be applied by hand (hand lay-up) or shotcreting when strengthening large surfaces. The hand lay-up method includes prewetting the base concrete with water for 1-3 days depending on the conditions of the base concrete and the surrounding climate. The moisture conditions in the transition zone between the base concrete and mortar are further discussed in [65], where it is found that the best bond is obtained when the base concrete has just dried back from a saturated surface. Prior to mounting the MBC system the base concrete surface has to be primed using a silt-up product (primer) to prevent moisture transport from the wet mortar to the base concrete. A first layer of mortar is immediately applied to the primed surface. Next, the CFRP grid is placed on the first layer of mortar followed by an additional layer of mortar being applied on top of the grid. The thickness of the mortar depends on the maximum grain size in the mortar.

Reliability of the system highly depends on the bond in two interface layers, between the concrete substrate and the first layer of mortar and in the between the grid in the mortar; see [66].

\section{Mineral-Based Strengthening at Material Level}

On the interface between the base concrete and the strengthening layer interface, such as between the fibre composite and the mortar, bond is crucial for the performance of the strengthening system. In a TRC or MBC system, bond between FRP and mortar relies mostly on mechanical interlocking (physical bond). If the mortar contains PVA fibres, a chemical bond is also being built up within the mortar phase. Good (but not overly strong) bond together with the deformation compatibility of the mortar and
PVA fibres, results in fibre bridging and as a consequence, multiple cracking and overall strain hardening, resulting in a "stronger" and more ductile mortar. These mechanisms are detailed below.

5.1. Bond between Base Concrete and Strengthening Layer. When an existing RC element is to be strengthened, the tensile force developed in the strengthening layer must be introduced into the original concrete of the member by bond forces. Failure can initiate from an interfacial defect causing delamination of the whole strengthening layer in the case of a "weak" bond and spalling in the case of an overly "strong" bond [35].

Bond strength in a mineral-based system generally depends on the adhesion in the interface, friction, aggregate interlocking and possibly, time-dependent factors [52].

The sensitivity of a structure to bond strength depends highly on what kind of load it is subjected to. The force transmission into the original concrete when strengthening for flexure occurs over a relatively large length (surface). In contrast, the force transmission via shear strengthening takes place only in the range behind the last shear crack [9]. As a result, significantly shorter anchorage lengths and "better bond", and in some cases, additional anchoring is required for shear strengthening. An example is a TRC-reinforced Tbeam strengthened for shear [9] where if the U-wrap around its web is not anchored into the slab via an L-shaped steel section the TRC reinforcement has a tendency to peel away from the web.

Incompatibility between the base concrete and the repair material in repair and/or strengthening systems can lead to the same bond problem and render the system ineffective resulting in debonding or spalling of the strengthening layer especially if the load is applied parallel to the bond line of the combined system. If there is an incompatibility in the elastic modulus of the base concrete and the mortar, it will result in the incompatibility of the deformations on the interface as the "weaker" material will have larger deformations [67]. If the load bearing capacity of the material or the bond at the transition zone is exceeded by the transferred load, failure will occur. Recommendations for the modulus of elasticity of the repair or strengthening material suggest a modulus at least 30\% larger than the modulus of elasticity for the base concrete [68]. When the bonding agent tensile load bearing capacity is exceeded in the interface between the base concrete and the strengthening layer, the strengthening would peel off the structure. To prevent debonding, it is usual to prescribe a minimum adhesive tensile strength of the original concrete substrate which, for example, in German codes is $1.5 \mathrm{~N} / \mathrm{mm}^{2}$ [9]. If the surface is roughened adequately, by means of removing the deteriorated parts and sandblasting, a good bond can be guaranteed. Another parameter that influences the compatibility of the combined repair or strengthening system is the drying shrinkage. As the fresh repair or strengthening material has a tendency to shrink, the more or less older base concrete acts as a rigid foundation that restrains these movements. These differential movements cause tensile stresses in the repair or strengthening material and compressive stresses in the base 


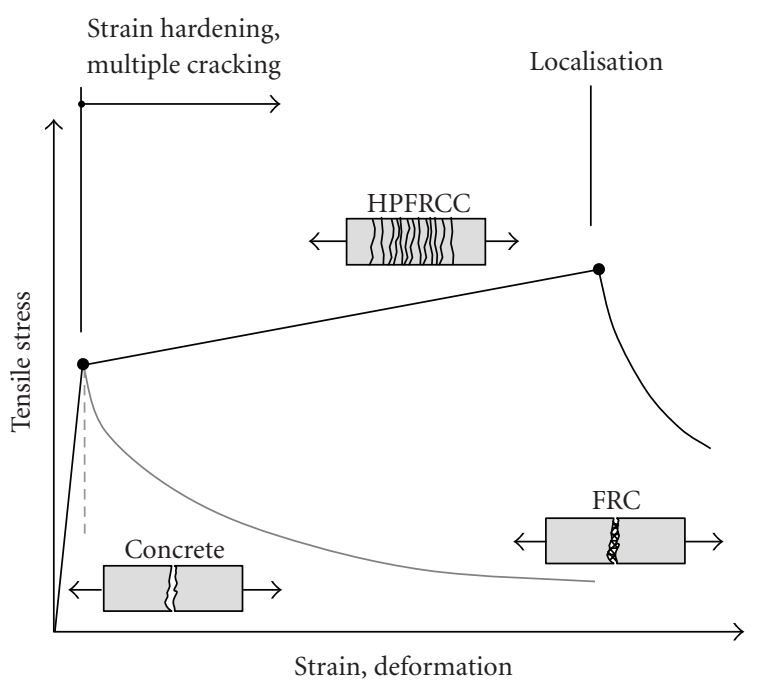

Short fibre reinforced mortar/concrete [70]

(a)

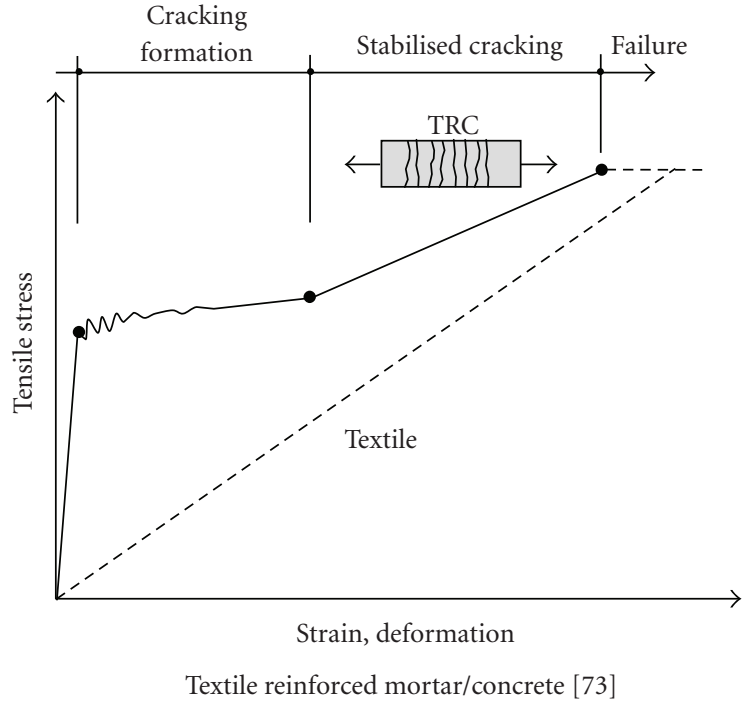

(b)

FIgURE 4: (a) Strain hardening and strain softening mortars. (b) Tensile behaviour of TRC.

concrete. Creep in this context can be an advantage since it releases parts of these stresses. Shrinkage incompatibility is more associated with cement-based mortars while the polymer-modified mortars (PMC) show better shrinkage compatibility and epoxy mortars proved to have the best shrinkage compatibility [68].

5.2. Bond of FRP in a Mortar. The mineral-based strengthening systems are strongly dependent on the bond between fibre composite and mineral-based binder. Using a nonimpregnated textile fabric with a high density (high fibre filament amount) will make it hard for the mineral-based binder to penetrate. This type of inferior bond or penetration of textile fabrics has been the focus for researchers developing the TRC system $[8,11,14]$. Using an epoxy-impregnated CFRP grid, as in the MBC system, relies on physical bond between CFRP and mortar. This physical bond can originate from direct mechanical anchorage (joints in the grid, transversal tows of the grid), frictional forces on the interface, aggregate or fibre interlock (if the mortar contains longer fibres) but there is no chemical bond between the FRP and the mortar as in an epoxy-bonded system there would be.

When using strain hardening mortars, there is a chemical bond between the mortar fine-grain aggregates and the PVA fibres which affects bonding of the embedded FRP reinforcement in the mortar. PVA has a high chemical bond and reaches its peak load at relatively small pullout length. During the extraction process, it has a tendency to break instead of pulling out from the mortar. In order to increase the opening of an individual crack and enhance the composite stress-strain behaviour of PVA-ECC, the chemical and frictional bond of the PVA fibre is to be decreased, for example, by means of particular surface treatment (coating) [38] or by modification of the fibre/matrix interface transition zone. Bond can be lessened, for example, by adding fly ash to the mix.
Bond characteristics influence the mechanism of load transfer between reinforcement and concrete, and therefore control the concrete (or mortar) crack spacing, crack width, required concrete cover to the reinforcement, and the reinforcement development length. The behaviour of strengthened concrete structures thus depends on the integrity of the bond. Most literature to date has been published about bond of FRP bars in concrete or other cementitious matrices. Very little literature is found on the bond of FRP grids to a cementitious material which is more complex because of the geometry of the grid, including the formation of the joints.

5.3. Multiple Cracking—Crack Control through Strain hardening Materials. The deformation behaviour of cementitious composites (concrete, fibre-reinforced concrete) and high performance fibre-reinforced cement composites (HPFRCCs) is typically distinguished according to their tensile stress-strain characteristics and postcracking response [69]. In [70], it is shown that brittle matrices, such as plain mortar and concrete, lose their tensile load-carrying capacity almost immediately after formation of the first crack as illustrated in Figure 4.

The addition of fibres in conventional fibre-reinforced concrete (FRCs) can increase the toughness of cementitious matrices significantly; however, their tensile strength and especially strain capacity and ductility beyond first cracking are not enhanced [71]. FRC is therefore considered to be a quasibrittle material with tension softening behaviour, that is, a decaying load and immediate localization of composite deformation at first cracking in the FRC matrix. In contrast, strain hardening fibre-reinforced cementitious composites (SHCCs), which is a particular class of HPFRCC (high performance fibre-reinforced cementitious composites), are defined by an ultimate strength higher than their first cracking strength and the formation of multiple cracking 
during the inelastic deformation process. Under tension, it initially exhibits multiple cracking with associated overall hardening, which later changes to softening as fracture localizes [72]. The crack continues to open, and the embedded fibres are pulled out of the matrix (or break, depending on what matrix/fibre composition is used), which still generates some resistance against crack opening within the tensile softening regime. When all fibres are completely pulled out (or broken), no resistance is left, that is, the tensile stress is equal to zero.

The contribution of a cementitious matrix to the loaddeformation response of reinforced concrete or ECC is the so-called "strain hardening" or "plastic hardening". Tensile softening versus tensile hardening behaviour is illustrated in Figure 4(a). Textile-Reinforced concrete exhibits a similar hardening behaviour [73, 74]; however the cracking process is clearly not as uniform as in an ECC (Figure 4(b)). In the precracking regime (Stage I), the stresses are distributed until the first cracking strength of the concrete is reached. First cracking occurs at the point where the ultimate tensile strength of the concrete is reached and the FRP reinforcement will carry the entire applied load in the vicinity of the transverse crack location. The load carried by the concrete in the uncracked segments is transferred to the FRP reinforcement at the crack location via interfacial bond. After first crack formation (Stage IIa, "cracking formation"), the load-deformation curve shows a small increase in loading capacity as compared to that in Stage I due to the formation of additional transverse cracking. The member is softened by the formation of additional $\operatorname{crack}(\mathrm{s})$ and the load increase per deformation increment is decreasing with each crack until Stage IIb when a stabilized crack pattern is reached (postcracking regime). When the final crack pattern is being formed, the slope of the stress strain relationship becomes steeper again, which mainly results from the Young's modulus of the fibre-reinforcement. Crack widths are also governed by the FRP reinforcement and the bond characteristics to the surrounding concrete matrix. At this stage of a stabilized crack pattern (Stage III) no further cracking occurs. Here, mainly the FRPs determine the stiffness of the member. Stage III is characterized either by slippage in the fibre tows instead of yielding of steel reinforcement, or by linear elastic deformations until the FRP ruptures in a brittle manner upon reaching its tensile failure strain, as detailed in [75]. In practice, final failure normally is a combination of fibre slippage and rupture [73].

Due to the more homogeneous nature (as a consequence of randomly distributed, well mixed short fibres) of ECC, there is a gradually increasing part of the curve smoother than for TRC because of the fibre bridging characteristics of the PVA fibres compared to those of a textile mesh. In ECC, there is no definite distinction between stages IIa and IIb (crack saturation) [36]. The (pseudo)strain-hardening behaviour in ECC is achieved by sequential development of matrix multiple cracking [76]. "Multiple cracking" means that under tension, cracks are consecutively formed after first cracking, and become evenly and closely spaced. Deformation then is often expressed in terms of strain instead of crack opening displacement. Multiple cracking results in the improvement in "ductility, toughness, fracture energy, strain hardening, strain capacity and deformation capacity under tension, compression or bending" [77].

The strain hardening ensures that a structural element made of such a composite material will maintain its stability also after cracking. This is a significant difference between all conventional FRC and SHCC materials as shown in Figure 4. Deformation of ECC is uniform on a macroscale and considered as pseudostrain, which is a material property [36], in contrast to other reinforced concrete-like materials such as conventional FRC. As a consequence of the strain hardening, the tensile strain capacity and ultimate strength in the cracked state of ECC are much higher than that of conventional (steel) fibre-reinforced concrete.

5.4. Fibre Bridging. Since the overall hardening behaviour highly relies on fibre bridging, it is important to know how high bridging stresses arise in the fibres. This would also limit and determine which materials are usable as reinforcing fibres. For very flexible fibres which have a high strain capacity (polymeric fibres), a snubbing effect (fibre dowel action arising when a fibre is not loaded in the direction of the initial straight fibre) may occur reducing the fibre critical length leading to premature failure. For elastoplastic fibres (steel), local yielding can happen, as for elastic-brittle fibres (carbon, glass) fibre failure may happen due to bending of fibres [39]. The fibre bridging analysis is about relating the single fibre bridging stress to the crack opening which is a function of fibre and interface properties and mode of failure [78]. Fibre properties may include the fibre modulus, ultimate tensile strength, fibre length, diameter, and the interface properties are the cohesive strength, fracture properties and frictional properties. The micromechanics of fibre bridging is described more in detail by [79]. In a composite, the embedded fibres in the mortar would often bridge a crack at an angle. Inclined fibre pullout would depend on a greater number of parameters, involving the inclination angle of the fibre to the matrix crack plane, local fibre/matrix interaction properties and possible aging effects (interfacial properties and fibre/matrix interaction changing with time) [79].

Fibre bridging after first cracking of the cement matrix is well detectable in PVA-reinforced mortars. For MBC systems, the mechanism is important because with adequately chosen mortars, a MBC system can be altered/improved resulting in a more efficient strengthening material under tension or shear.

\section{Testing MBC Systems}

As previously shown in Figure 1, the three (material, component and structural) levels of mineral-based strengthening must be linked together. It is not within the scope of this paper to generalize about all existing mineral-based strengthening systems; however linking can be done and is presented for mineral-based composites through experimental investigations carried out at LTU and DTU.

Mineral-based composites are, as defined earlier, a particular instance of mineral-based strengthening in which 


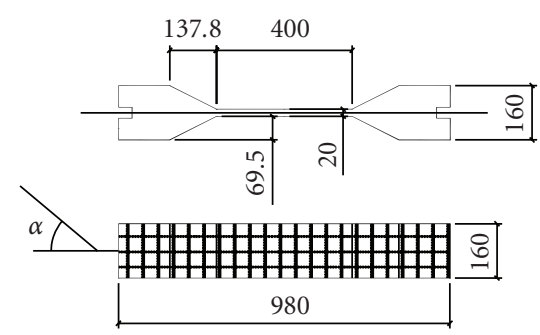

(a) Uniaxial tension
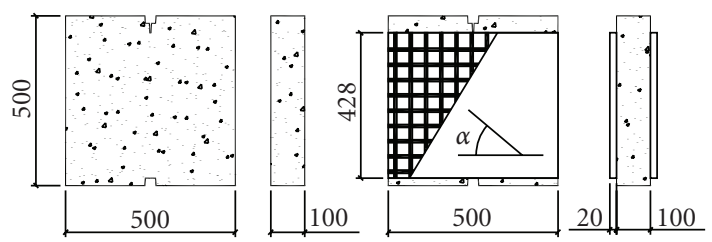

(b) Wedge splitting test

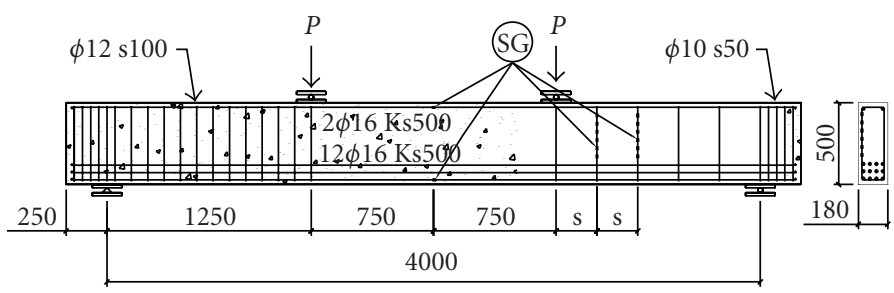

(d) Shear strengthening
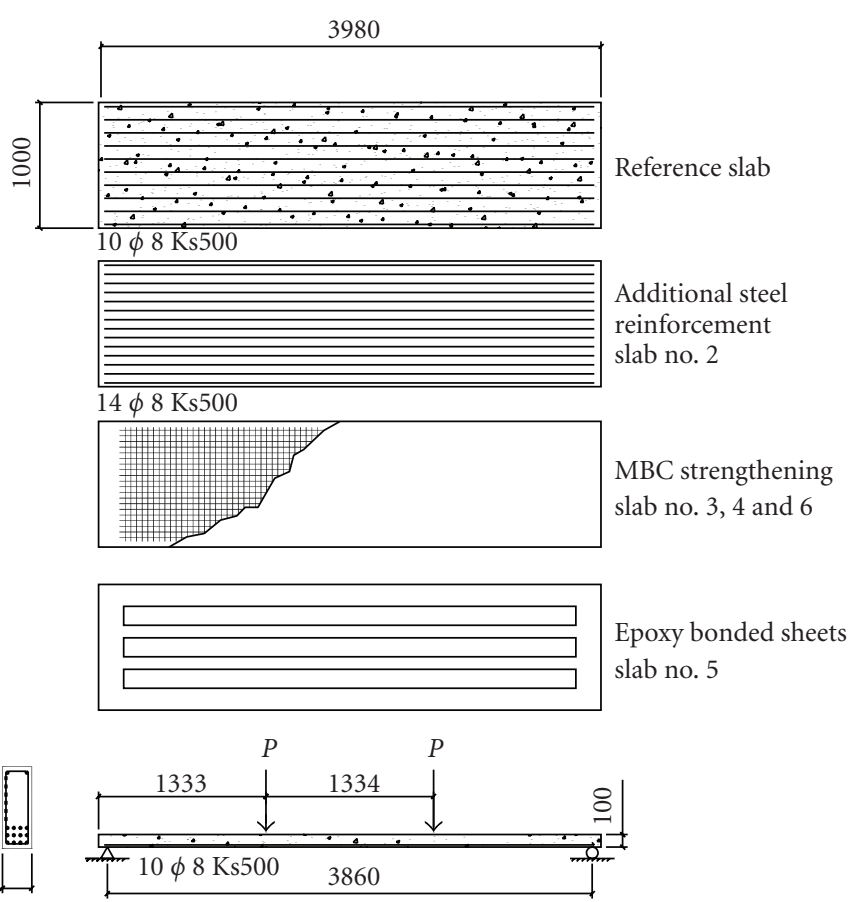

(c) Flexural strengthening

FIGURE 5: Experimental tests for tensile and fracture behaviour: (a) uniaxial tensile test on dogbones. (b) wedge-splitting test, (c) flexural beams, and (d) shear beams.

FRP grids are adhered to the concrete substrate by means of (quasibrittle or strain hardening) mortars. By using ECC as the mortar phase in MBC, different force transfer mechanisms come into play which did not exist in the initial phase of $\mathrm{MBC}$ research where the mortar was a quasibrittle PMM. In addition to that, MBC research has mostly focused on beams strengthened in flexure and shear, and much less attention has been paid to repairing structural members in which significant tensile forces may emerge. Before applying the $\mathrm{MBC}$ as a strengthening material in conditions where the structural member is subject to tensional or splitting forces (or bending combined with axial forces), it is necessary to properly characterize the tensile behaviour. Knowledge of related parameters such as the tensile strain-crack opening curve makes possible estimations, for example, about brittleness in compression and tension or shear capacity. Suitable test methods are being searched, which quantify the tensile properties of MBC directly (dogbone tests) or indirectly (WST, giving the splitting tensile strength).

This section will give insight in the MBC behaviour for tension, flexure and shear. Tests have been performed on the tensile behaviour of the MBC system, dogbone and wedge splitting tests (WST), along with flexural and shear strengthening, see Figure 5 where all tests are shown.

6.1. Experimental Set-Up. A summary of tests conducted at LTU and DTU is shown in Figure 5. Uniaxial tensile and wedge-splitting tests aim to characterize the tensile and fracture properties of the strengthening material. Shear and flexural strengthening (Figure 8) involving MBC lead towards the structural level and applications as outlined in Figure 1. Short descriptions of each test are summarized below, and further references are given to a more detailed description of each.

6.2. Material Properties. All the material properties for the materials used in the four different tests are summarized in Table 1 for the CFRP grids and Table 2 for the binders.

\subsection{Linking Material and Component Levels}

6.3.1. Uniaxial Tensile Tests. New test method and test specimens have been developed for testing MBC under uniaxial tension in [64]. The bare strengthening material was tested, without considering the interaction with a real structure to be strengthened. Quasibrittle polymer-modified mortars and ECC have been investigated together with an embedded CFRP grid in the mid-plane of the dogbone-shaped specimens, focusing on crack development and the influence of the applied mortar's ductility on the behaviour in tension.

Dimensions of the dogbone-shaped test specimens were $160 \times 160 \times 980 \mathrm{~mm}$, with a representative test section of $400 \times 160 \times 20 \mathrm{~mm}$. Two different grids with different grid spacings and three chosen grid orientations $\left(0^{\circ}-\right.$ longitudinally placed grid, $90^{\circ}$ - transversally placed grid, $15^{\circ}$ - rotated grid) were tested in different combinations, more in detail presented in [64]. The number of the CFRP tows in the representative test section, tensile direction, were 
TABLE 1: Mechanical properties for the fibres in each tow of the CFRP grids used in experimental tests [53].

\begin{tabular}{llcccc}
\hline Material & Direction & $\begin{array}{c}\text { Tow spacing } \\
{[\mathrm{mm}]}\end{array}$ & $\begin{array}{c}\text { Tensile strength } \\
{[\mathrm{MPa}]}\end{array}$ & $\begin{array}{c}\text { E modulus } \\
{[\mathrm{GPa}]}\end{array}$ & $\begin{array}{c}\text { Failure strain } \\
{[\% \text { o }]}\end{array}$ \\
\hline Grid S & Transverse & 25 & 5214 & 366 & 14.0 \\
Grid S & Longitudinal & 24 & 3546 & 278 & 12.5 \\
Grid M & Transverse & 43 & 4620 & 389 & 11.9 \\
Grid M & Longitudinal & 42 & 4219 & 404 & 10.5 \\
Grid L & Transverse & 72 & 3772 & 423 & 8.6 \\
Grid L & Longitudinal & 70 & 3877 & 320 & 12.8 \\
\hline
\end{tabular}

TABLE 2: Material properties for binders used in experimental tests.

\begin{tabular}{lccc}
\hline Material & Description & $\begin{array}{c}\text { Tensile strength } \\
{[\mathrm{MPa}]}\end{array}$ & $\begin{array}{c}\text { Compressive strength } \\
{[\mathrm{MPa}]}\end{array}$ \\
\hline PMM & Polymer-modified mortar & 2.4 & 53.2 \\
ECC & Engineered cementitious composite & 3.0 & 60.0 \\
\hline
\end{tabular}

7 (small grid) and 4 (medium grid). The specimens were fixed in self-centering, custom-made clamps.

In Figure 6(a), quasibrittle and ductile mortars are compared and related to the linear elastic behaviour of the pure CFRP grid. Behaviour of all specimens was nearly identical up to first cracking irrespective of which mortar is used. After first cracking, ECC specimens show a significant strain hardening behaviour with both small (S) and medium (M) grids which is represented as the contribution of the mortar compared to the shifted lines of the pure grid. The ECC specimens, after the first crack, show a further load increase until the peak load. These curves are smooth due to the fibre-bridging characteristics of the cracks in ECC. Curves of quasibrittle mortars are more jagged and have a significant drop in load carrying capacity right after the first crack (and after further crack formation). This fact shows that the increased ductility of the ECC mortar has a positive effect on the interaction with the CFRP through the fibre bridging effect. It seems to prevent premature failure of the CFRP grid which was observed in the specimens with brittle mortars, with significantly reduced axial tensile strength.

Figure 6(b) illustrates the effect of the grid orientation. The apparent better performance of the grid when rotated transversally may be due to an epoxy surplus on the transversal tows resulting in improved mechanical anchorage or, more likely, due to the joint shape (between longitudinal and transversal tows of the grid) and associated deformation capacity of the grid joints when loaded in a certain direction.

6.3.2. Wedge Splitting Tests. Brittleness of concrete-like materials is usually evaluated by means of the post failure behaviour in tension governed by the stress versus crack width relation $(\sigma-\mathrm{w})$, the so-called softening behaviour which is a basic property of a (conventional) concrete described by the tensile strength, the maximum crack width and the fracture energy, which corresponds to the area under the stress versus crack width curve. WST (wedge splitting test), originally introduced by [80] and further improved by [81] is a suitable method, traditionally used for brittle materials, for obtaining the splitting tensile strength along with the postpeak behaviour, and an estimation on the fracture energy.

WST is an extension of the uniaxial test because the $\mathrm{MBC}$-strengthening is applied on a concrete surface. In a recently published study [63], behaviour of a CFRP grid reinforcement in two different directions $\left(0^{\circ}\right.$ and $45^{\circ}$, resp.) together with quasibrittle and ductile mortars has been investigated and evaluated through recording and comparing crack widths, crack patterns, splitting load versus crack opening displacement curves and fracture energy values for the MBC-strengthened concrete specimens. External dimensions of the plain concrete test specimen were $500 \times$ $500 \times 100 \mathrm{~mm}$, after strengthening with a representative test section of $400 \times 420 \times 140 \mathrm{~mm}$ where $140 \mathrm{~mm}$ is the total thickness after strengthening on both sides. The length of the starter notch together with the groove is $50 \mathrm{~mm}$. The bottom groove served to ease proper vertical positioning and acted as a line support for the heavy specimens. The CFRP grid was applied on both sides (ten tows bridging the crack on both sides, in the nonrotated position), placed between two $10 \mathrm{~mm}$ thick layers of mortar, applied on the concrete surface roughened with sandblasting and treated with a primer to enhance bond on the concrete-mortar interface. Tests were run deformation-controlled, that is, through the crack opening displacement kept constant at $0.3 \mathrm{~mm} / \mathrm{min}$, by a clip gauge mounted at the tip of the notch in the midplane of the specimen. During the test, vertical load and crack opening displacement (COD) are recorded, hence the splitting load can be calculated.

The resulting splitting force versus crack opening displacement plots show that the splitting tensile strength of concrete can be significantly improved with MBCstrengthening, resulting in an increase of $30-110 \%$ in peak splitting load compared to the unstrengthened reference specimen (Figure 7). ECC has given significantly higher failure loads and similarly to the uniaxial tests, it prevented pronounced drops in load capacity. Ductility is significantly 


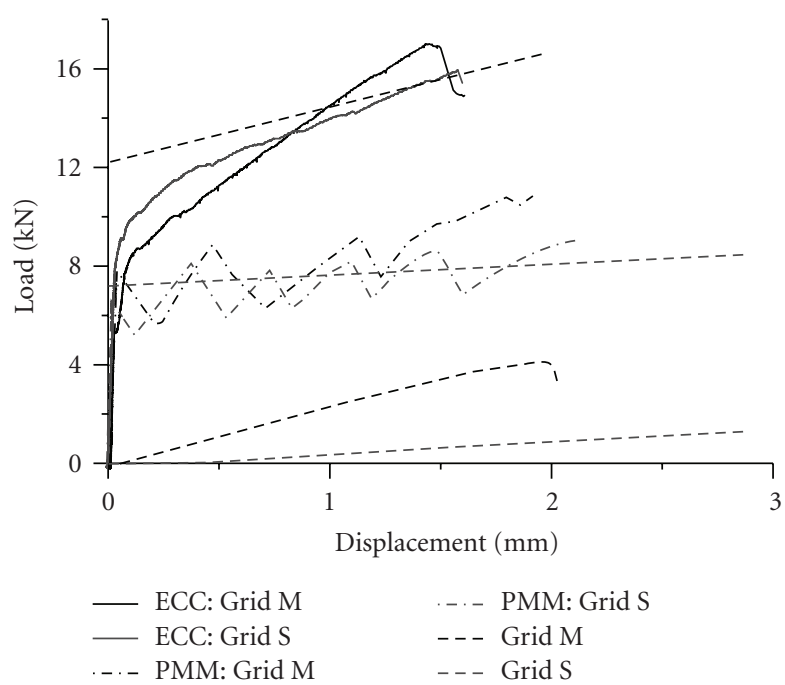

(a)

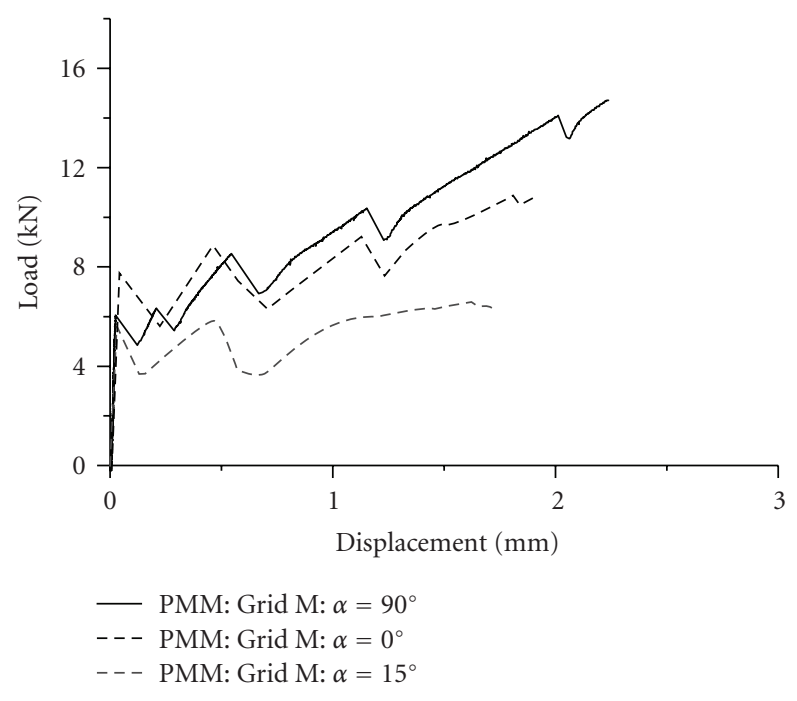

(b)

Figure 6: (a) All dogbone specimens with grid S and M placed in longitudinal $\left(0^{\circ}\right)$ direction. (b) Effect of grid orientation $\left(\right.$ transverse $\left(90^{\circ}\right)$, longitudinal $\left(0^{\circ}\right)$ and rotated in $\left.15^{\circ}\right)$.

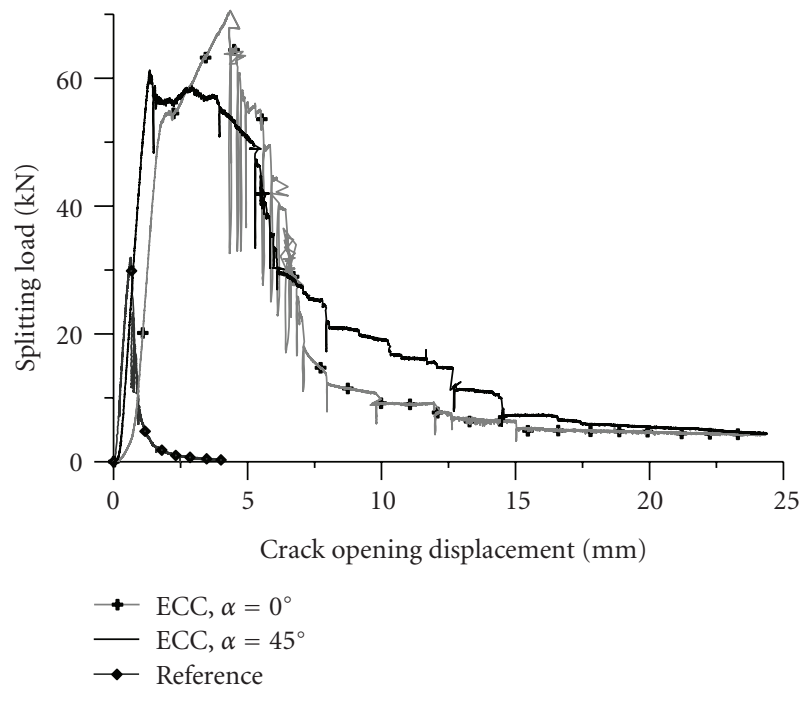

(a)

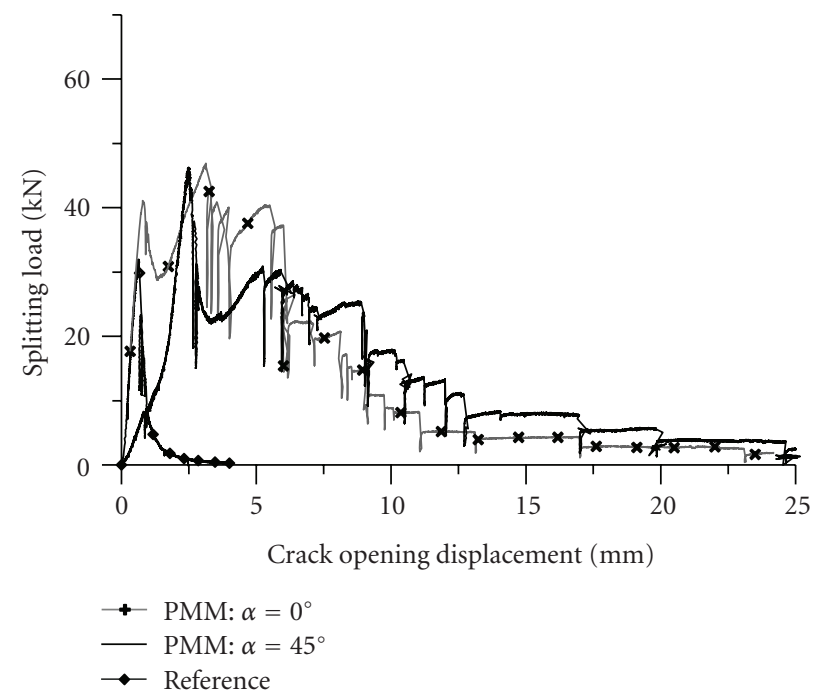

(b)

FIGURE 7: Splitting force versus COD curves for specimens with highest peak load per series, against reference specimen (plain concrete).

enhanced by all grid-mortar combinations resulting in an extreme increase of fracture energy which is directly proportional to the area under the curves.

Bond provided by both mortars was excellent leading to CFRP rupture. By applying PVA-reinforced ductile ECC as bonding agent, improved performance, significantly higher fracture energy, multiple cracking and enhanced ductility were observed, caused by improved bond between grid and mortar due to the refined grain structure, the bridging effect of the embedded fibres working against crack opening and via direct mechanical interlock with the grid.

Compared to a uniaxial tensile test, WST also has provided information on the softening part of the curve after peak load, revealing tendencies in how fast or how gradually load capacity decreases until all crack bridging fibre tows and embedded fibres in the mortar are broken. The slopes of the $F_{s}$ versus COD curves reveal that the tensile ductility (recorded peak load and its tendency to decrease to zero) depends more on the grid orientation than on the mortar quality, unlike the increase in the energy absorption/fracture energy which seems to be "mortar-dependent" and is significantly higher for the ECC specimens.

\subsection{Linking Component and Structural Levels}

6.4.1. Slabs Strengthened in Flexure. The test set-up and geometry for the slab specimens is shown in Figure 5 and a more detailed overview and results are also published in $[82,83]$. Three of the slabs were strengthened using the MBC system, one specimen with one CFRP grid, one specimens 


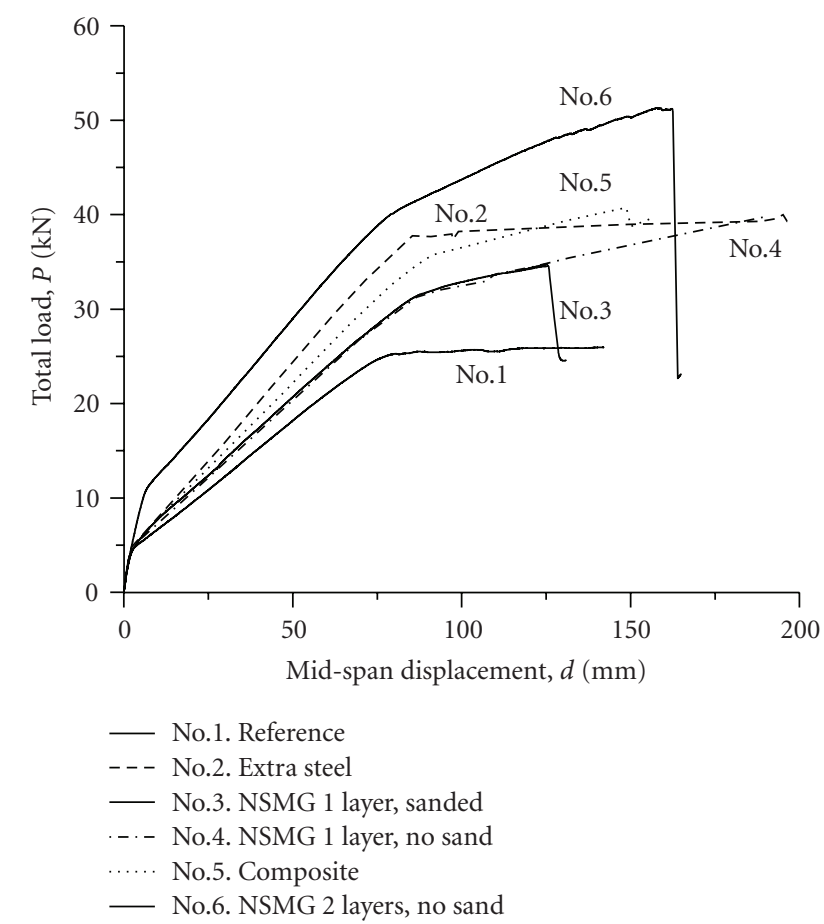

Figure 8: Load versus mid-span displacement of flexural strengthened specimens.

with a sanded CFRP for better mechanical anchorage and one specimen with double CFRP grid. In addition one specimen was strengthened using epoxy-bonded carbon fibre sheets and yet one specimen containing four extra flexural steel reinforcement bars, the extra reinforcement was calculated to correspond to the strengthening. Thus, all of the specimens were designed to have similar failure loads, except the specimen with dual CFRP grid. The thickness of the strengthening layer was approximately $10 \mathrm{~mm}$ and a quasibrittle mortar was used as binder. In all MBCstrengthened specimens the CFRP grid had a fibre content of $159 \mathrm{~g} / \mathrm{m}^{2}$ (Grid M). For the epoxy-based strengthening, the carbon fibre sheets had a fibre content of $200 \mathrm{~g} / \mathrm{m}^{2}$. The total carbon fibre amount in the tensile direction of the specimens corresponded to $20 \mathrm{~mm}^{2} / \mathrm{m}$ (CFRP grid) and $62 \mathrm{~mm}^{2} / \mathrm{m}$ (carbon fibre sheet) respectively.

All of the strengthened slabs increased the ultimate bearing capacity in comparison to the nonstrengthened reference beam. Strengthened specimens using one layer of CFRP grid failed at a total load of $35 \mathrm{kN}$ and specimen with epoxy-bonded sheet failed at $41 \mathrm{kN}$ while showing a stiffer behaviour compared to the latter. The specimen containing four extra flexural bars failed at a load of $38 \mathrm{kN}$, similar loads to the specimens with only one grid. However, the specimen with extra steel reinforcement showed stiffer response compared to both the specimens strengthened with sheets and one CFRP grid. It is also noted that sanding the surface of the grid (specimen No. 3) led to premature rupture of the CFRP grid. Strengthening the specimen with dual layer of CFRP grid will have a positive effect on the load bearing capacity. Thus this specimen (No. 6) had the highest ultimate load capacity of $51 \mathrm{kN}$. All of the specimens with the
MBC system failed by fibre rupture while the epoxy-based strengthening system failed by a mix mode of debonding and fibre rupture. Comparative load-displacement curves are plotted in Figure 8.

6.4.2. Beams Strengthened in Shear. Beams strengthened in shear had a rectangular cross section and were $4.5 \mathrm{~m}$ long and had a height of $0.5 \mathrm{~m}$. Again, these results are described in more detail in $[53,66]$. Note, in Figure 8, that the beams were heavily shear reinforced in one shear span and had inferior to no shear reinforcement in the other shear span. Thus, only the shear span containing no or little shear reinforcement was strengthened. In these experiments, the influence of different grids and internal steel shear reinforcement ratios were studied. In all test the quasibrittle PMM was used as a binder of the strengthening system. The PMM was also used in the dogbone and WST tensile test. For testing the influence of different CFRP grids, the carbon fibre amount was varied from 66,98 , to $159 \mathrm{~g} / \mathrm{m}^{2}$ (Grid S, $\mathrm{L}$, and M). All of these specimens had no internal shear reinforcement in the strengthened shear span. For specimens with different internal shear reinforcement the different distances was $\mathrm{s}=$ $350 \mathrm{~mm}$ and $\mathrm{s}=250 \mathrm{~mm}$, see also Figure 5. The internal shear reinforcement was monitored by six strain gauges mounted on both two stirrups closest to the load, see Figure 5. In addition, six strain gauges were mounted on the vertical CFRP tows in the grid at the same locations as the strain gauges mounted on the stirrups.

All of the specimens with no internal shear reinforcement and strengthened with the MBC system failed by fibre rupture of the vertical tows. For strengthened specimens with different internal reinforcement amounts the failure mode changed from a brittle shear failure to a more ductile compressive/crushing failure. The ultimate loads for all specimens are summed in Table 3 together with compressiveand tensile strength of the concrete, and failure modes (S-shear failure and C-compression/crushing). From the results of the specimens strengthened with different grids it was clear that the specimens with highest carbon fibre amount had the highest load bearing capacity. Since the specimens containing internal shear reinforcement were heavily monitored by strain gauges, the shear behaviour and strain development from initial load stages could be measured. Here, the strain development in the stirrups was reduced for beams strengthened with the MBC system. The strains monitored in the CFRP grid indicated that high strain concentrations were apparent in the vicinity of cracks.

Typical strain readings from internal shear reinforcement and CFRP grid are shown in Figure 9 for specimens with and without strengthening corresponding to specimens with concrete compressive strength of $47-52 \mathrm{MPa}$ and internal stirrup distance of $350 \mathrm{~mm}$ (Specimens C35s3 and C35s3Grid $M$ in Table 3). Figures 9(a) and 9(b) shows that strains in the (steel) stirrups are reduced in all MBC-strengthened beams even at relatively low load levels $(100-200 \mathrm{kN})$ when compared to the nonstrengthened ones. As the shear load increases, the favourable strain reduction of the MBC system is more pronounced for a strengthened specimen compared to a non strengthened specimen. 
TABLE 3: Ultimate shear loads and failure modes, along with description of tested shear beams.

\begin{tabular}{|c|c|c|c|c|c|c|c|}
\hline Beam & Binder & CFRP & $\begin{array}{l}\text { Stirrup distance } \\
{[\mathrm{mm}]}\end{array}$ & $\begin{array}{l}\text { Failure load } \\
{[\mathrm{kN}]}\end{array}$ & Failure mode & $\begin{array}{c}\text { Compressive strength } \\
{[\mathrm{MPa}]}\end{array}$ & $\begin{array}{c}\text { Tensile strength } \\
{[\mathrm{MPa}]}\end{array}$ \\
\hline C40s0 & - & - & - & 123.5 & $S$ & 44.8 & 2.9 \\
\hline $\mathrm{C} 40 \mathrm{~s} 0^{*}$ & - & - & - & 126.7 & S & 36.3 & 2.5 \\
\hline $\mathrm{C} 40 \mathrm{~s} 0-\mathrm{M}$ & PMM & - & - & 141.9 & S & 53.6 & 2.8 \\
\hline C40s0-Grid M & PMM & Grid M & - & 244.9 & $S$ & 53.6 & 2.8 \\
\hline C40s0-Grid M & PMM & Grid M & - & 241.9 & S & 53.6 & 2.8 \\
\hline C40s0-Grid S* & PMM & Grid S & - & 208.1 & $S$ & 32.5 & 2.7 \\
\hline C40s0-Grid M* & PMM & Grid M & - & 251.9 & S & 35.1 & 3.0 \\
\hline C40s0-Grid L* & PMM & Grid L & - & 206.4 & S & 44.8 & 2.5 \\
\hline $\mathrm{C} 35 \mathrm{~s} 0$ & - & - & - & 130.6 & $\mathrm{~S}$ & 47.0 & 2.7 \\
\hline $\mathrm{C} 35 \mathrm{~s} 3$ & - & - & 350 & 346.0 & $\mathrm{C}+\mathrm{S}$ & 47.6 & 3.1 \\
\hline C35s3-Grid M & PMM & Grid M & 350 & 336.9 & C & 52.4 & 3.0 \\
\hline
\end{tabular}

* Tests were run not deformation-controlled but load-controlled at $10 \mathrm{kN} / \mathrm{sec}$.

In the vertical CFRP tows, a significantly uneven strain distribution is visible, with locally high strains in the vicinity of forming shear cracks. These strains are increasing rapidly as the shear crack is opening.

6.5. Field Implementations. The MBC-strengthening system should be able to be implemented in various field strengthening applications such as, harbour structures (less sensitive to moisture compared to epoxy-bonded strengthening systems), large structures that requires higher compatibility of the strengthening system to the base concrete structure, low temperature applications, applications that demand diffusion openness and for concrete applications that excludes the use of epoxies. In addition, the MBC system can be used in tunnelling or mining applications instead of using steel fibre-reinforced shotcrete. In the latter, the combination of using ECC as a binder should further improve the ductility and crack bridging ability of the MBC system. Pilot studies for in-situ production techniques of the MBC system using quasibrittle mortars as binders have been investigated in [82]. The results from this study clearly show that spraying the MBC system can be made in an easy and efficient manner. The application technique is done by mounting the CFRP grid on preattached studs and then the binder is being sprayed. The thickness of the MBC system is controlled by the chosen length of the studs.

6.6. Discussion and Conclusions. Uniaxial tests have revealed that the most commonly used grid (medium-sized, M-grid) performs better when placed in transversal direction. This leads to the need of studying the effect of grid joint formations (i.e., the grid is "woven" out of two perpendicular tows of CFRP and the grid joint looks differently depending on the direction). The uneven distribution of the residual epoxy on the grid surface in the two perpendicular directions could also contribute to the direction-dependent performance.

Flexural specimens strengthened with $\mathrm{MBC}$ had higher ultimate load compared to the epoxy-bonded sheets of comparing the fibre amount in the tensile direction. However, the failure mode for the $\mathrm{MBC}$ was fibre rupture while the epoxybonded carbon fibres failed by a mix mode of debonding and fibre rupture. However, trying to improve the bond between the mineral-based binder and the CFRP grid by the use of sand-coated grids has negative effects on ultimate load bearing capacity. It appears that sanding the surface creates discrete increases in strain and leading to premature failure, this was however not monitored. But as shown in the shear strengthening in Figure 9(b), by the use of monitoring strains in the grid, discrete high strains occur in the vicinity of cracks.

All MBC-strengthened shear beams, which had no internal shear reinforcement, failed by rupture of the vertical tows in the grid. From this series of specimens it was concluded that increasing the fibre amount will also increase the ultimate failure load, to what extent is not within the scope of this paper. But increasing the fibre to a certain level should imply failure in the intermediate transition zone between binder and fibre composite. For beams withinternal reinforcement the failure mode changed from a brittle shear failure to a more ductile compressive failure. For the specimens withinternal reinforcement it could be seen from strain gauge monitoring that the $\mathrm{MBC}$-strengthening system reduced strains in the steel reinforcement even for low shear loads. Thus, this indicates that the MBC-strengthening system can be used for crack width reduction in the service limit state.

MBC tests have shown that strain hardening mortars can be successfully used together with embedded FRP reinforcement and the fibre bridging behaviour of ECC "compensates" for the brittleness of the grid and prevents premature failure of it by retaining fast and rigid deformations in the grid joints. This may enable a better utilization of the grid.

To the authors' knowledge, ECC has been implemented into the $\mathrm{MBC}$ system for the first time. Due to its fibre bridging mechanisms and strain hardening behaviour, ECC shall further be tested as a bonding agent for mineral-based strengthening systems. Preliminary results from pullout tests carried out by the authors have shown that if the application 


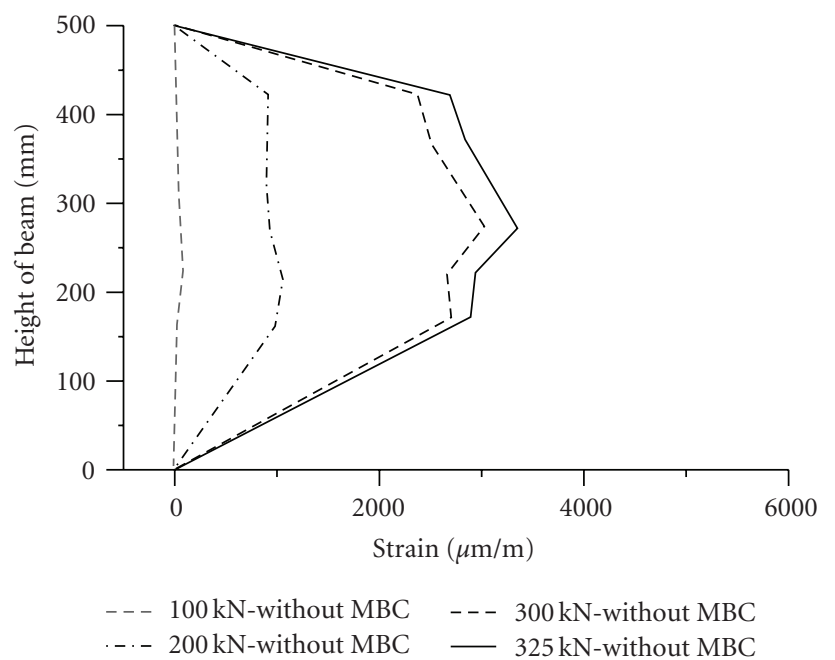

(a)

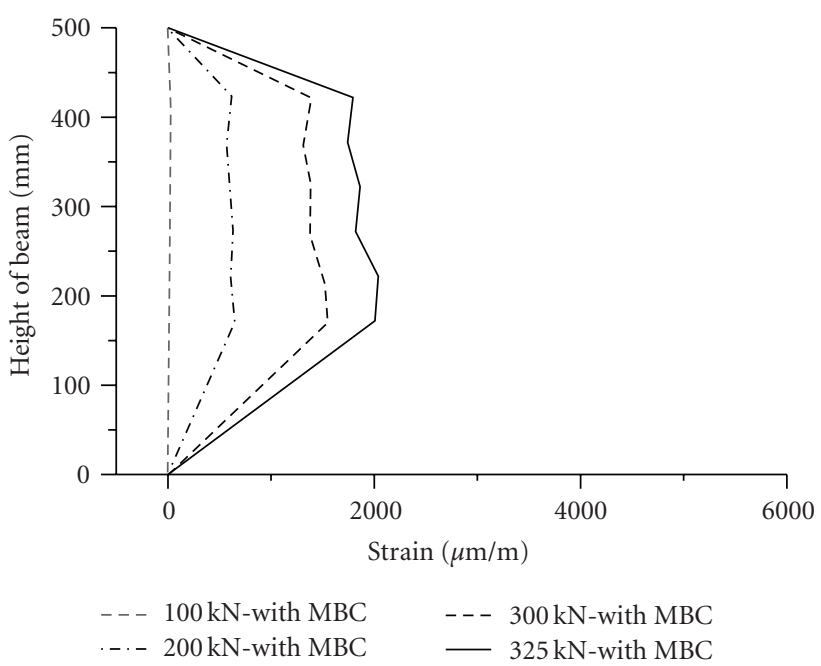

(b)

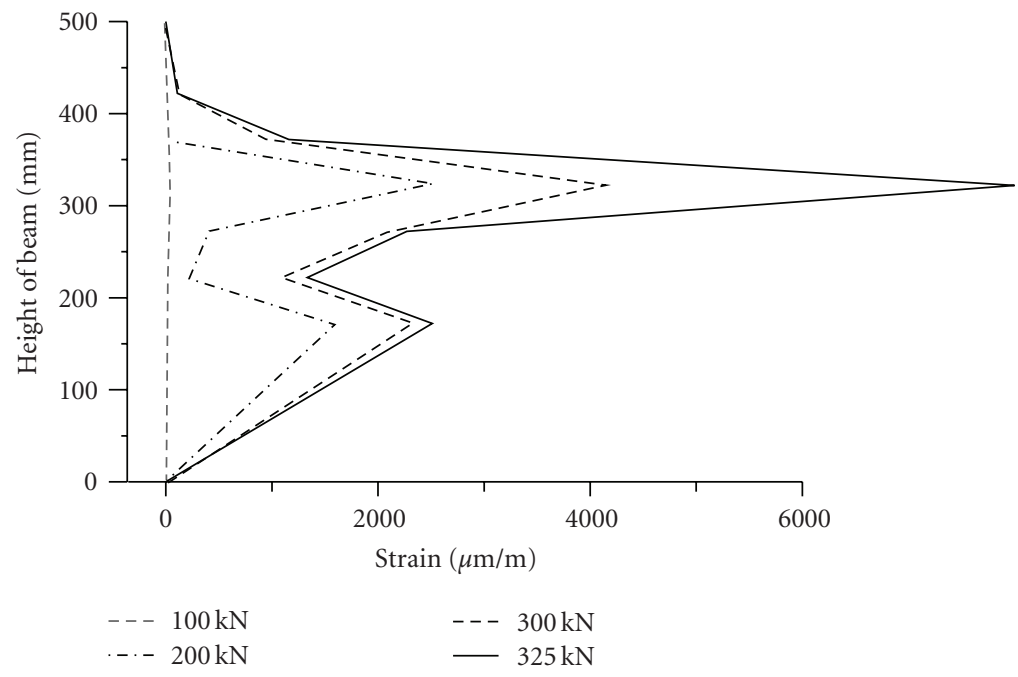

(c)

FIGURE 9: Strain development at different shear loads. (a) in stirrups without MBC and (b) in stirrups with MBC and (c) strains in vertical CFRP tows.

method is correct and the mix is properly compacted around the CFRP grid, there is a nearly perfect bond on the interface even at short embedment lengths $(45 \mathrm{~mm})$ using both polymer-modified quasibrittle mortars and ECC. Therefore in a real structural element, the failure mode is expected to be fibre rupture.

Traditionally, ECC has been used up to its maximum strain or deformation capacity (especially where energy dissipation is the major concern). In an ECC-based MBC, the FRP component is fully used up to its maximum potential; however the ECC is not because the FRP reinforcement fails prior to that the ECC would reach its maximum strain capacity. In a structural member made from pure ECC, the maximum strain capacity would be characterized by the highest yet sustainable crack density with evenly distributed fine cracks.

Despite the fact that when combined with FRP, the maximum strain capacity of the ECC is not fully utilized,
ECC improves the MBC system significantly. Its main advantages are that it accommodates larger elongations than FRP therefore it will not be the weak link in strengthening, it enforces the failure mode to be more ductile [49] and prevents or reduces sudden brittle deformations. Its documented spalling resistance $[46,47]$ is also very attractive when designing externally bonded strengthening systems.

\subsection{Future Research for $M B C$}

6.7.1. Materials. Strain hardening mortars together with FRP grids should be further tested especially in shear beams or other shear sensitive structures where it should yield a more predictable and ductile failure mode.

Tri- or other multiaxial grids could also be effectively used, in particular for shear strengthening. More flexible grids, in which the joints are not rigid using a more elastic matrix for impregnating the fibres, would most likely 
accommodate larger deformability of the grids for the use of, for example, wrapping. Also investigations of incorporating higher fibre amount in the CFRP grid should be made for further increasing the load bearing capacity.

When using ECC as binder, further investigation is needed on whether (and to what extent) the large improvement in load capacity is due to a direct tensile contribution from the ECC or the fact that it is capable to retain grid joints from fast and brittle deformations breaking the grid or to slow down this process, hence preventing premature failure in the grid.

6.7.2. Structural Behaviour and Future Applications. Influences on the bond in the transition zone between fibre composite and binder should be investigated when increasing the fibre amount in the FRP grids. The investigations done so far on the MBC system has shown no problems concerning the bond to the base concrete structure, future applications involving enhancing the load bearing capacity should be followed by an experimental program involving the bond to the base concrete.

For field applications the influence of shrinkage should also be investigated, especially when incorporating ECC as a binder. However, traditional precautions can be taken when commercially available PMM is used as binders.

Regarding future applications, stay-in-place formwork could be one new approach, especially for the combination of using concrete with low-quality as a core material and then using high-quality binders together with a FRP grid as a protective outer layer of remaining formwork.

To incorporate the MBC system for the use in civil engineering structures design guidelines should be developed for estimating the load bearing capacity.

\section{Discussion and General Conclusions in Mineral-Based Strengthening}

7.1. Guidelines. One of the most important aspects for implementing these mineral-based systems for the use in real structures is that there exist engineering design methods for calculating the load bearing capacity. To the authors' knowledge, there exists no general and commonly accepted design for the mineral-based system. These guidelines should be made on a sound physical basis dealing with both the favourable aspects at the service limit state (crack bridging and crack reducing effects) together with the load bearing increase in the ultimate limit state.

7.2. Production Methods and Procedures. For strengthening larger surfaces, sprayed ECC together with FRP grid reinforcement may be a solution. Although this paper has not dealt with sprayable ECC there has been publications about the topic, see, for example, [84]. As the tensile strength of the pure ECC is not significantly different from that of a concrete, combining it with FRP would be useful when the tensile stresses significantly exceed the upper load bearing capacity of an additional pure ECC strengthening layer.

7.3. Suitable Materials. Perhaps it is an advantage to strengthen a structure using a textile for increasing the ductility at ultimate failure load due to the relatively poor bond between binder and fibre composite. However, for service limit state a full utilization of interfacial bond between FRP and mortar is desirable to maintain economy. This justifies the applicability of grid-type reinforcement if the shape of the cross-section allows a grid to be used. It is important to emphasize that epoxy coating, compared to the textiles used in TRC, significantly improves the interaction between mortar and FRP because of the difficulties of the mortar to penetrate dry fibre bundles.

An alternative to TRC when ductility is an issue is strainhardening mortars together with grids as published in [63, 64]. Strain-hardening mortars also offer the advantage of a more ductile and predictable failure mode which would be beneficial for strengthening shear sensitive structures.

It is assumed that ECC, when combined with grids, would be able to ensure a more even stress distribution among the grid tows along a crack line because of its fibre bridging effect. Then the peak strains in the adjacent grid tows (as shown, e.g., in Figure 9(b)) would be reduced and redistributed to the neighbouring tows hence making the failure more predictable.

New matrices could also be introduced for impregnating the FRP component. A common method for strengthening columns or beams is wrapping with textiles or continuous sheets/dry fibres. However, wrapping is not possible when using an epoxy-impregnated carbon fibre grid due to the rigidness and brittleness of the matrix. Using textiles makes wrapping around corners much easier [83]. Using a semielastic matrix, for example, latex, which still ensures rigid connection points but allows wrapping around corners, could be a beneficial solution for ensuring rigidity, anchorage and effectiveness of the fibres.

7.4. Interactions. Further research should be directed to the influence of bonding, both between base concrete and binder along with the transition zone and between binder and fibre composite. In $\mathrm{MBC}$, having perfect bond between fibre composite and quasibrittle binder could lead to premature failure in the FRP. In TRC, bond between textile and mortar is significantly weaker and there is a limitation of how many layers of textile can be used effectively without anchorage problems (if there is no additional mechanical anchorage) and debonding. This also limits the maximum fibre amount applicable in a certain direction and therefore the maximum strengthening effect achievable by a TRC system.

Penetration of the FRP component has been a problematic issue with several existing systems (e.g., dry fibres/sheets, TRC). Using nonimpregnated sheets, grids or textiles will generate larger slips and inferior effective strain over the roving cross section with possibly overloaded yarns. Using impregnated fibres (fibres imbedded in an epoxy matrix) will create a more effective strain distribution in the FRP tow such as in case of FRP grids.

7.5. Other Issues. Further research should also be directed to the durability and fatigue aspects of mineral-based strengthening. In seismic regions, ductility and energy dissipation capacity is of importance, in this regard ECC-based systems 
which use additional fibre composites as reinforcement could be further developed and investigated.

\section{Acknowledgments}

The research work presented in this paper was performed at the Technical University of Denmark and Luleå University of Technology, financed by the Norwegian Research Council through the strategic institute program RECON at Norut Narvik Ltd, the Swedish road administration, and the development fund of the Swedish construction industry. Sto Scandinavia should also be acknowledged for supplying materials in the experimental studies.

\section{References}

[1] A. Carolin, Carbon fibre reinforced polymers for strengthening of structural elements, Doctoral thesis, Luleå University of Technology, Luleå, Sweden, 2003.

[2] B. Täljsten, "FRP strengthening of existing concrete structures," in Design Guideline, Luleå University of Technology, Luleå, Sweden, 2006.

[3] U. Meier, "Bridge repair with high performance composite materials," Material und Technik, vol. 4, pp. 125-128, 1987.

[4] T. C. Triantafillou, "Shear strengthening of reinforced concrete beams using epoxy-bonded FRP composites," ACI Structural Journal, vol. 95, no. 2, pp. 107-115, 1998.

[5] A. Nanni, "Concrete repair with externally bonded FRP reinforcement," Concrete International, vol. 17, no. 6, pp. 22 26, 1995.

[6] H. Ohuchi, S. Ohno, H. Katsumata, et al., "Seismic strengthening design technique for existing bridge columns with CFRP," in Proceedings of the 2nd International Workshop on Seismic Design and Retrofitting of Reinforced Concrete Bridges, R. Park, Ed., pp. 495-514, Queenstown, New Zealand, 1994.

[7] M. J. Chajes, T. F. Januszka, D. R. Mertz, T. A. Thomson Jr., and W. W. Finch Jr., "Shear strengthening of reinforced concrete beams using externally applied composite fabrics," ACI Structural Journal, vol. 92, no. 3, pp. 295-303, 1995.

[8] T. C. Triantafillou, C. G. Papanicolaou, P. Zissimopoulos, and T. Laourdekis, "Concrete confinement with textile-reinforced mortar jackets," ACI Structural Journal, vol. 103, no. 1, pp. 2837, 2006.

[9] A. Brückner, R. Ortlepp, and M. Curbach, "Anchoring of shear strengthening for T-beams made of textile reinforced concrete (TRC)," Materials and Structures, vol. 41, no. 2, pp. 407-418, 2008.

[10] A. Brückner, R. Ortlepp, S. Weiland, and M. Curbach, "Shear strengthening with textile reinforced concrete," in Proceedings of the 3rd International Conference on Composites in Construction, pp. 1307-1314, Lyon, France, 2005.

[11] T. C. Triantafillou and C. G. Papanicolaou, "Textile Reinforced Mortars (TRM) versus Fibre Reinforced Polymers (FRP) as strengthening materials of concrete structures," in Proceedings of the 7th ACI International Symposium on Fibre-Reinforced (FRP) Polymer Reinforcement for Concrete Structures, C. K. Shield, J. P. Busel, S. L. Walkup, and D. D. Gremel, Eds., pp. 99-118, American Concrete Institute, 2005, SP-230.

[12] V. C. Li, "Engineered cementitious composites," in Proceedings of the 3rd International Conference on Construction Materials (ConMat'05), Vancouver, Canada, August 2005.

[13] J. Mirza, M. S. Mirza, and R. Lapointe, "Laboratory and field performance of polymer modified cement-based repair mortars in cold climates," Construction and Building Materials, vol. 16, pp. 365-374, 2002.

[14] M. Raupach, J. Orlowsky, T. Büttner, and A. Keil, "Recent developments of the usage of polymers in textile reinforced concrete," in Proceedings of the 5th Asian Symposium on Polymers in Concrete, pp. 53-60, Taramani, India, 2006.

[15] D. Van Gemert, L. Czarnecki, M. Maultzsch, et al., "Cement concrete and concrete-polymer composites: two merging worlds: a report from 11th ICPIC Congress in Berlin, 2004," Cement and Concrete Composites, vol. 27, no. 9-10, pp. 926933, 2005.

[16] S. Pascal, A. Alliche, and Ph. Pilvin, "Mechanical behaviour of polymer modified mortars," Materials Science and Engineering A, vol. 380, no. 1, pp. 1-8, 2004.

[17] M. Schleser, B. Walk-Lauffer, M. Raupach, and U. Dilthey, "Application of polymers to textile-reinforced concrete," Journal of Materials in Civil Engineering, vol. 18, no. 5, pp. 670-676, 2006.

[18] P. Garcés, J. Fraile, E. Vilaplana-Ortego, D. Cazorla-Amorós, E. G. Alcocel, and L. G. Andión, "Effect of carbon fibres on the mechanical properties and corrosion levels of reinforced Portland cement mortars," Cement and Concrete Research, vol. 35, no. 2, pp. 324-331, 2005.

[19] A. Peled and A. Bentur, "Geometrical characteristics and efficiency of textile fabrics for reinforcing cement composites," Cement and Concrete Research, vol. 30, no. 5, pp. 781-790, 2000.

[20] Y. Wang, H. C. Wu, and V. C. Li, "Concrete reinforcement with recycled fibres," Journal of Materials in Civil Engineering, vol. 12, pp. 314-319, 2000.

[21] P. S. Song, S. Hwang, and B. C. Sheu, "Strength properties of nylon and polypropylene-fibre-reinforced concretes," Cement and Concrete Research, vol. 35, pp. 1546-1550, 2005.

[22] D. A. Silva, A. M. Betioli, P. J. P. Gleize, H. R. Roman, L. A. Gómez, and J. L. D. Ribeiro, "Degradation of recycled PET fibres in Portland cement-based materials," Cement and Concrete Research, vol. 35, pp. 1741-1746, 2005.

[23] T. Ochi, S. Okubo, and K. Fukui, "Development of recycled PET fiber and its application as concrete-reinforcing fiber," Cement and Concrete Composites, vol. 29, no. 6, pp. 448-455, 2007.

[24] A. M. Betioli and D. A. Silva, "Evaluation of durability of PET fibers under diverse aggressive environments," in Proceedings of the 10th International Conference on Durability of Building Materials and Components (DBMC'05), pp. 1-7, Lyon, France, 2005.

[25] $\mathrm{K} . \mathrm{Wu}$ and J. Zhou, "The influence of the matrix-aggregate bond on the strength and brittleness of concrete," in Bonding in Cementitious Composites, S. Mindess and S. P. Shah, Eds., vol. 114 of Symposium Proceedings, pp. 29-34, Materials Research Society, Pittsburgh, Pa, USA, 1988.

[26] K. Mitsui, Z. Li, D. A. Lange, and S. P. Shah, "Relationship between microstructure and mechanical properties of the paste-interface," ACI Materials Journal, vol. 91, pp. 30-39, 1994.

[27] Y. L. Wong, L. Lam, C. S. Poon, and F. P. Zhou, "Properties of fly ash-modified cement mortar-aggregate interfaces," Cement and Concrete Research, vol. 29, no. 12, pp. 1905-1913, 1999.

[28] I. Ahmed, Use of Waste Materials in Highway Constructions, Noyes Data Corporation, Westwood, NJ, USA, 1993.

[29] S. Chandra, Waste Materials Used in Concrete Manufacturing, Noyes, Westwood, NJ, USA, 1997.

[30] M. Urban, "Properties of hardened self-compacting concrete with fly ash," in Proceedings of the 3rd International Scientific 
Conference on Quality and Reliability in Building Industry, pp. 533-538, Levoča, Slovak Republic, 2003.

[31] R. F. Feldman, G. G. Carette, and V. M. Malhotra, "Studies on mechanics of development of physical and mechanical properties of high-volume fly ash-cement pastes," Cement and Concrete Composites, vol. 12, no. 4, pp. 245-251, 1990.

[32] Z. Rudzionis and E. Ivanauskas, "Investigations in properties of self-compacting concrete modified by fly ash admixture," in Proceedings of the 8th International Conference on Modern Building Materials, Structures and Techniques, E. K. Zavadskas, P. Vainiunas, and F. M. Mazzolani, Eds., pp. 151-156, Vilnius, Lithuania, 2004.

[33] B. Mobasher, A. Peled, and J. Pahilajani, "Pultrusion of fabric reinforced high flyash blended cement composites," in Proceedings of the 6th International RILEM Symposium on Fibre-Reinforced Concretes (BEFIB '04), pp. 1473-1482, 2004.

[34] S. Xu and Q. Li, "An experimental study on bending behavior of cementitious composites reinforced in combination with carbon textile and short-cut PVA fiber," in Advances in Construction Materials, C. U. Grosse, Ed., pp. 237-254, 2007.

[35] V. C. Li, "Repair and retrofit with Engineered Cementitious Composites," in Proceedings of the 3rd International Conference on Fracture Mechanics of Concrete and Concrete Structures (FraMCoS '98), pp. 1715-1726, AEDIFICATIO, Freiburg, Germany, 1998.

[36] G. Fischer and V. C. Li, "Influence of matrix ductility on tension-stiffening behavior of steel reinforced Engineered Cementitious Composites (ECC)," ACI Structural Journal, vol. 99, no. 1, pp. 104-111, 2002.

[37] S. Wang and V. C. Li, "Tailoring of PVA fibre/matrix interface for Engineered Cementitious Composites (ECC)," in Proceedings of the Fibre Society Symposium on Advanced Flexible Materials and Structures: Engineering with Fibre, pp. 91-92, Loughborough, UK, 2003.

[38] M. Maalej, T. Hashida, and V. C. Li, "Effect of fibre volume fraction on the off-crack plane energy in strain hardening Engineered Cementitious Composites," Journal of American Ceramics Society, vol. 78, no. 12, p. 3375, 1995.

[39] V. C. Li and Y. W. Chan, "Determination of interfacial debond mode for fibre reinforced cementitious composites," ASCE Journal of Engineering Mechanics, vol. 120, no. 4, pp. 707-719, 1994.

[40] V. C. Li, "Reflections on the research and development of Engineered Cementitious Composites (ECC)," in Proceedings of the JCI International Workshop on Ductile Fibre Reinforced Cementitious Composites (DFRCC)—Application and Evaluation (DRFCC '02), pp. 1-21, Takayama, Japan, 2002.

[41] V. C. Li, G. Fischer, Y. Kim, et al., "Durable link slabs for jointless bridge decks based on strain hardening cementitious composites," Research Progress Report, Michigan Department of Transportation, Ann Arbor, Mich, USA, 2003.

[42] H. Fukuyama, Y. Matsuzaki, K. Nakano, and Y. Sato, "Structural performance of beam elements with PVA-ECC," in Proceedings of the 3rd International Workshop on High Performance Fibre Reinforced Cement Composites (HPFRCC '99), H. W. Reinhardt and A. Naaman, Eds., pp. 531-542, Chapman \& Hull, 1999.

[43] G. Parra-Montesinos and J. K. Wight, "Seismic response of exterior RC column-to-steel beam connections," Journal of Structural Engineering, vol. 126, no. 10, pp. 1113-1121, 2000.

[44] S. L. Billington and J. K. Yoon, "Cyclic response of unbonded posttensioned precast columns with ductile fiber-reinforced concrete," Journal of Bridge Engineering, vol. 9, no. 4, pp. 353 363,2004 .
[45] G. Fischer and V. C. Li, "Intrinsic response control of momentresisting frames utilizing advanced composite materials and structural elements," ACI Structural Journal, vol. 100, no. 2, pp. 166-176, 2003.

[46] Y. M. Lim and V. C. Li, "Durable repair of aged infrastructures using trapping mechanism of Engineered Cementitious Composites," Cement and Concrete Composites, vol. 19, no. 4, pp. 373-385, 1997.

[47] T. Kanda, T. Saito, and N. Sakata, "Tensile and anti-spalling properties of direct sprayed ECC," Journal of Advanced Concrete Technology, vol. 1, no. 3, pp. 269-282, 2003.

[48] P. Suthiwarapirak, T. Matsumoto, and T. Kanda, "Flexural fatigue failure characteristics of an engineered cementitious composite and polymer cement mortars," JSCE Journal of Materials, Concrete Structures and Pavements, vol. 718, no. 57, pp. 121-134, 2002.

[49] V. C. Li, "Large volume, high-performance applications if fibres in civil engineering," Journal of Applied Polymer Science, no. 83, pp. 660-686, 2002.

[50] A. Kamal, M. Kunieda, N. Ueda, and H. Nakamura, "Evaluation of crack opening performance of a repair material with strain hardening behavior," Cement and Concrete Composites, vol. 30, no. 10, pp. 863-871, 2008.

[51] V. C. Li and J. Kong, "Self-compacting Engineered Cementitious Composites (Self-compacting ECC)," January 2009, http://ace-mrl.engin.umich.edu/NewFiles/invention/sc abstract.html.

[52] "Guide for the design and construction of externally bonded FRP systems for strengthening concrete structures," Tech. Rep. ACI 440.2R-02, ACI Committee, 2002.

[53] T. Blanksvärd, Strengthening of concrete structures by the use of mineral based composites, Licentiate thesis, Luleå University of Technology, Luleå, Sweden, 2007.

[54] A. Peled, A. Bentur, and D. Yankelevsky, "Effects of woven fabric geometry on the bonding performance of cementitious composites: mechanical performance," Advanced Cement Based Materials, vol. 7, no. 1, pp. 20-27, 1998.

[55] A. Badanoiu, "Improvement of the bond between carbon fibres and cementitious matrices," Tech. Rep., Royal Institute of Technology, Stockholm, Sweden, 2001.

[56] A. Wiberg, Strengthening of concrete beams using cementitious carbon fibre composites, Doctoral thesis, Royal Institute of Technology, Stockholm, Sweden, 2003.

[57] A. Badanoiu and J. Holmgren, "Cementitious composites reinforced with continuous carbon fibres for strengthening of concrete structures," Cement and Concrete Composites, vol. 25, no. 3, pp. 387-394, 2003.

[58] H. C. Wu and P. Sun, "Fibre reinforced cement based composite sheets for structural retrofit," in Proceedings of the International Symposium on Bond Behavior of FRP in Structures (BBFS '05), J. F. Chen and J. G. Teng, Eds., pp. 351356, Hong Kong, 2005.

[59] A. Keil and M. Raupach, "Improvement of the load-bearing capacity of textile reinforced concrete by the use of polymers," in Proceedings of the 12th International Congress on Polymers in Concrete (ICPIC '07), pp. 873-881, Chuncheon, Korea, 2007.

[60] T. Brockmann and W. Brameshuber, "Matrix development for the production technology of Textile Reinforced Concrete (TRC) structural elements," in Proceedings of the $3 r d$ International Conference on Composites in Construction, pp. 11651172, Lyon, France, 2005.

[61] T. C. Triantafillou and C. G. Papanicolau, "Shear strengthening of RC members with textile reinforced mortar (TRM) 
jackets," RILEM Journal of Materials and Structures, vol. 39, pp. $1-9,2006$.

[62] M. Curbach, "Verstärkung von Balken und Plattenbalken mit textilbewehrtem Beton," in SFB 528 Textile Bewehrungen zur Bautechnischen Verstärkung und Instandsetzung, pp. 433-462, 2005.

[63] K. Orosz and B. Täljsten, "Development of a new test method for Mineral Based Composites-wedge splitting test," in Proceedings of the 2nd International Conference on Concrete Repair, Rehabilitation and Retrofitting (ICCRRR '08), Cape Town, South Africa, 2008.

[64] B. Täljsten, K. Orosz, and G. Fischer, "Crack development in CFRP reinforced mortar-an experimental study," in Proceedings of the Asia-Pacific Conference on FRP in Structures (APFIS '07), S. T. Smith, Ed., pp. 671-676, 2007.

[65] J. Carlsvärd, Shrinkage cracking of steel fibre reinforced self compacting concrete overlays - test methods and theoretical modelling, Doctoral thesis, Luleå University of Technology, Luleå, Sweden, 2006.

[66] T. Blanksvärd, B. Täljsten, and A. Carolin, "Shear strengthening of concrete structures with the use of mineral-based composites (MBC)," Journal of Composites for Construction, vol. 13, no. 1, pp. 25-34, 2009.

[67] P. S. Mangat and F. J. O'Flaherty, "Influence of elastic modulus on stress redistribution and cracking in repair patches," Cement and Concrete Research, vol. 30, no. 1, pp. 125-136, 2000.

[68] K. E. Hassan, J. J. Brooks, and L. Al-Alawi, "Compatibility of repair mortars with concrete in a hot-dry environment," Cement and Concrete Composites, vol. 23, no. 1, pp. 93-101, 2001.

[69] ACI Committee 224, "Cracking of concrete members in direct tension,” Tech. Rep. ACI 224.2R-92, American Concrete Institute, Farmington Hills, Mich, USA, 1992.

[70] G. Fischer and V. C. Li, "Effect of fiber reinforcement on the response of structural members," Engineering Fracture Mechanics, vol. 74, no. 1-2, pp. 258-272, 2007.

[71] V. C. Li, "Performance driven design of fibre reinforced cementitious composites," in Proceedings of the 4th RILEM International Symposium on Fibre Reinforced Concrete, R. N. Swamy, Ed., pp. 12-30, Chapman and Hall, 1992.

[72] P. Kabele, S. Takeuchi, K. Inaba, and H. Horii, "Performance of Engineered Cementitious Composites in repair and retrofit: analytical estimates," in Proceedings of the 3rd International RILEM Workshop on High Performance Fiber Reinforced Cement Composites (HPFRCC '99), pp. 617-627, RILEM, Cachan, France, 1999.

[73] J. Hegger and S. Voss, "Textile reinforced concrete under biaxial loading," in Proceedings of the 6th RILEM Symposium on Fibre Reinforced Concrete (FRC) (BEFIB '04), pp. 14631472, Varenna, Italy, 2004.

[74] J. Hartig, U. Häußler-Combe, and K. Schicktanz, "Influence of bond properties on the tensile behaviour of Textile Reinforced Concrete," Cement and Concrete Composites, vol. 30, no. 10, pp. 898-906, 2008.

[75] W. Brameshuber, "Textile reinforced concrete: state-of-the-art report of RILEM technical committee 201-TRC, Tech. Rep., RILEM, Bagneux, France, 2006.

[76] E. H. Yang, Designing added functions in Engineered Cementitious Composites, Doctoral thesis, University of Michigan, Ann Arbor, Mich, USA, 2008.

[77] JCI-DFRCC Committee, "DFRCC terminology and application concepts," Journal of Advanced Concrete Technology, vol. 1, no. 3, pp. 335-340, 2003.
[78] V. C. Li, "From micromechanics to structural engineeringthe design of cementitious composites for civil engineering applications," Journal of Structural Mechanics and Earthquake Engineering, vol. 10, no. 2, pp. 37-48, 1993.

[79] V. C. Li, "Post-crack scaling relations for fibre reinforced cementitious composites," ASCE Journal of Materials in Civil Engineering, vol. 4, no. 1, pp. 41-57, 1997.

[80] H. N. Linsbauer and E. K. Tschegg, "Fracture energy determination of concrete with cube-shaped specimens," Zement und Beton, vol. 31, pp. 38-40, 1986.

[81] E. Brühwiler and F. H. Wittmann, "The wedge splitting test, a new method of performing stable fracture mechanics tests," Engineering Fracture Mechanics, vol. 35, no. 1-3, pp. 117-125, 1990.

[82] T. Blanksvärd and B. Täljsten, "Strengthening of concrete structures with cement based bonded composites," Journal of Nordic Concrete Research, vol. 38, pp. 133-153, 2008.

[83] B. Täljsten and T. Blanksvärd, "Mineral-based bonding of carbon FRP to strengthen concrete structures," Journal of Composites for Construction, vol. 11, no. 2, pp. 120-128, 2007.

[84] Y. Y. Kim, H.-J. Kong, and V. C. Li, "Design of Engineered Cementitious Composite suitable for wet-mixture shotcreting," ACI Materials Journal, vol. 100, no. 6, pp. 511-518, 2003. 

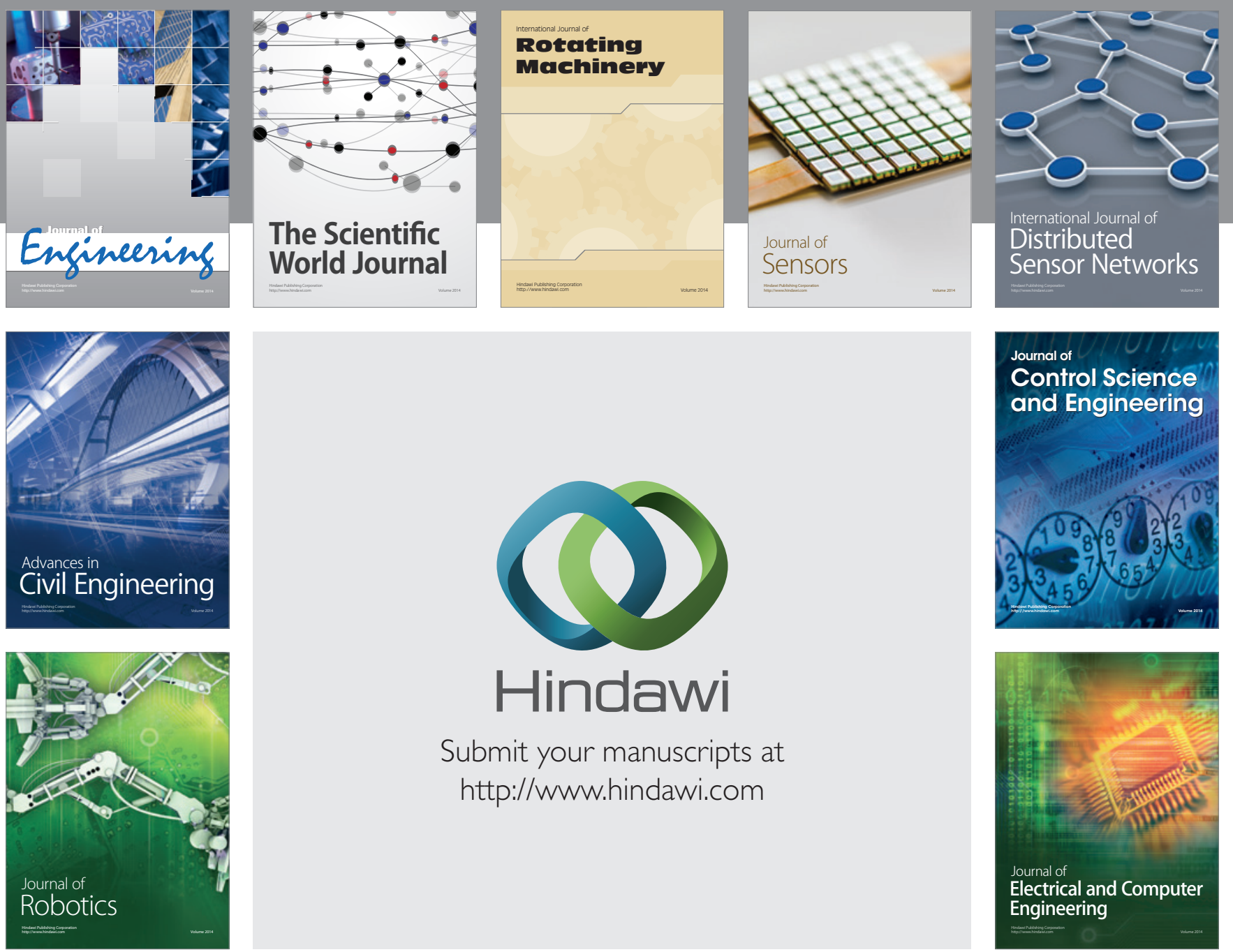

Submit your manuscripts at

http://www.hindawi.com
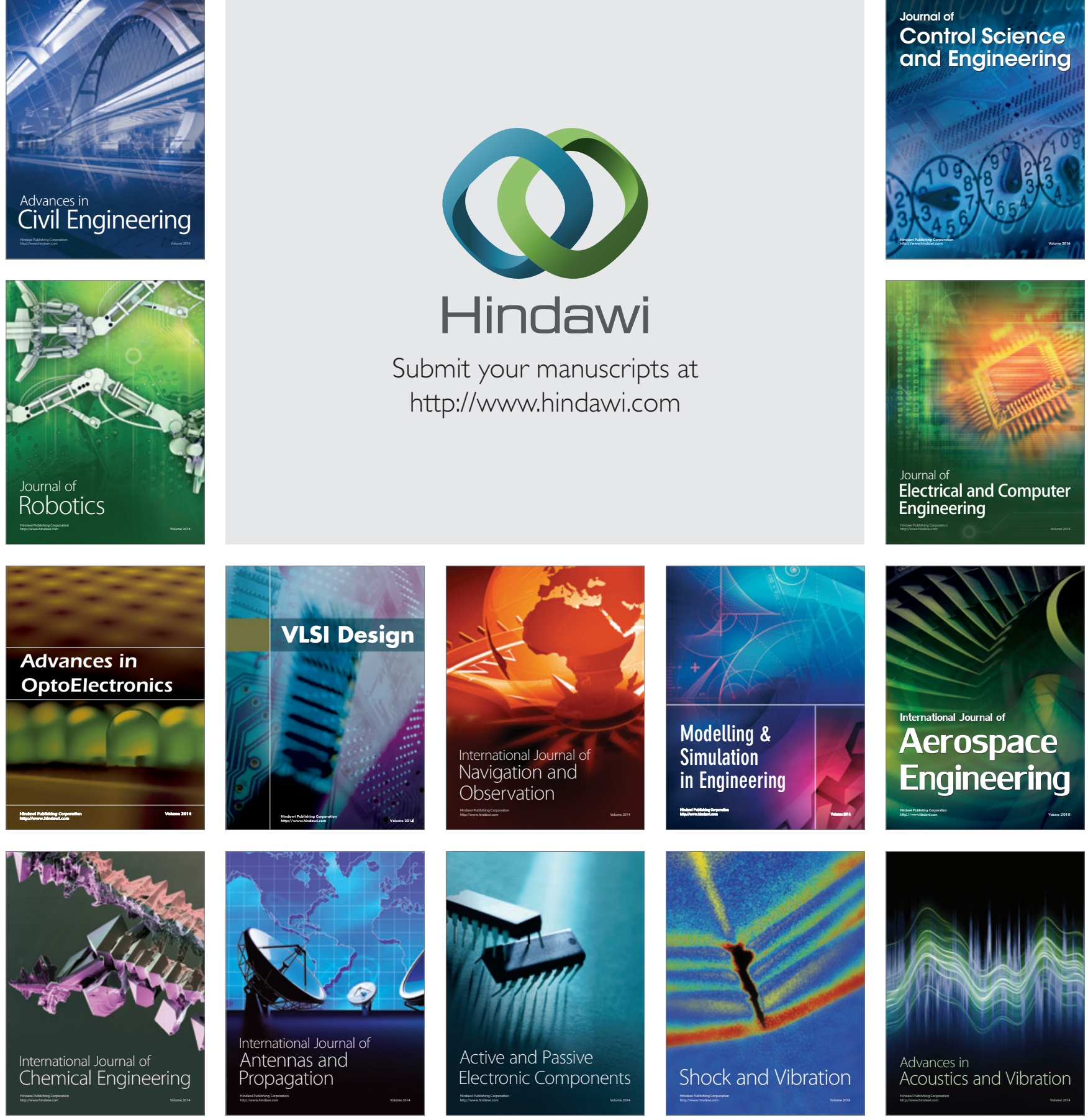